\title{
Mechanistic Aspects and Reaction Pathways for Oxidative Coupling of Methane on $\mathrm{Mn} / \mathrm{Na}_{2} \mathrm{WO}_{4} / \mathrm{SiO}_{2}$ Catalysts
}

\author{
Kazuhiro Takanabe ${ }^{\dagger}$ and Enrique Iglesia* \\ Department of Chemical Engineering, University of California at Berkeley, Berkeley, California 94720
}

Received: January 6, 2009; Revised Manuscript Received: March 15, 2009

\begin{abstract}
Kinetic and isotopic methods were used to determine the identity, rate constants, and reversibility of elementary steps for primary and secondary reactions involved in the oxidative coupling of methane (OCM) on $\mathrm{Mn} /$ $\mathrm{Na}_{2} \mathrm{WO}_{4} / \mathrm{SiO}_{2}$. We provide evidence in this study for parallel $\mathrm{C}-\mathrm{H}$ bond activation pathways, in which $\mathrm{H}$-abstraction is mediated by either oxygen species on surfaces or by $\mathrm{OH}$ radicals formed via $\mathrm{H}_{2} \mathrm{O} / \mathrm{O}_{2}$ equilibration on catalyst surfaces. OCM rates and $\mathrm{C}_{2}+$ yields are higher when $\mathrm{H}_{2} \mathrm{O}$ is present and $\mathrm{OH}$-mediated pathways prevail, because of the high reactivity of $\mathrm{OH}$ radicals and of their lesser sensitivity to the energy of the $\mathrm{C}-\mathrm{H}$ bond containing the hydrogen abstracted. These coupled homogeneous-catalytic sequences account for all observed kinetic effects of $\mathrm{O}_{2}, \mathrm{CH}_{4}$, and $\mathrm{H}_{2} \mathrm{O}$ on rates and selectivities for both $\mathrm{CH}_{4}$ conversion and for subsequent reactions of $\mathrm{C}_{2} \mathrm{H}_{6}, \mathrm{C}_{2} \mathrm{H}_{4}$ and $\mathrm{C}_{3}$ products; they are also consistent with measured kinetic and thermodynamic isotope effects for $\mathrm{C}-\mathrm{H}$ bond activation mediated by surface and $\mathrm{OH}$ radicals. Kinetic isotope effects and isotopic scrambling studies $\left(\mathrm{CD}_{4} / \mathrm{CH}_{4} ; \mathrm{D}_{2} \mathrm{O} / \mathrm{H}_{2} \mathrm{O} ;{ }^{18} \mathrm{O}_{2} /{ }^{16} \mathrm{O}_{2}\right)$ indicate that $\mathrm{C}-\mathrm{H}$ bond activation is irreversible and kinetically-relevant. $\mathrm{O}_{2}$ dissociation is quasi-equilibrated, but becomes irreversible as $\mathrm{H}_{2} \mathrm{O}$ / $\mathrm{O}_{2}$ ratios increase with increasing conversion and residence time. Competitive reactions of ${ }^{13} \mathrm{CH}_{4} / \mathrm{O}_{2}$ with ${ }^{12} \mathrm{C}_{2} \mathrm{H}_{6},{ }^{12} \mathrm{C}_{2} \mathrm{H}_{4}$, and ${ }^{12} \mathrm{C}_{3} \mathrm{H}_{6}$ with and without added $\mathrm{H}_{2} \mathrm{O}$ show that $\mathrm{H}$-abstraction from hydrocarbons is much less sensitive to $\mathrm{C}-\mathrm{H}$ bond strength when $\mathrm{OH}$ radicals are used to abstract hydrogen instead of oxide surfaces. Maximum $\mathrm{C}_{2+}$ yields require conditions that favor $\mathrm{OH}$-mediated pathways while maintaining equilibrium oxygen surface coverages and $\mathrm{OH}$ radical concentrations. $\mathrm{OH}$-mediated pathways are more sensitive to $\mathrm{O}_{2}$ pressure than surface-mediated pathways; thus, low $\mathrm{O}_{2}$ pressures and staging strategies that maintain stoichiometric $\mathrm{O}_{2}$ requirements and low local $\mathrm{O}_{2}$ pressures can improve $\mathrm{C}_{2}$ selectivities but only when $\mathrm{OH}$ radicals are maintained at equilibrium concentrations via catalytic $\mathrm{H}_{2} \mathrm{O}-\mathrm{O}_{2}$ reactions. These findings and interpretations indicate that intermediate $\mathrm{O}_{2}$ pressures give maximum $\mathrm{C}_{2+}$ yields, but that their optimal value depends sensitively on prevalent $\mathrm{H}_{2} \mathrm{O}$ concentrations as they vary with conversion along the reactor. These predictions about the consequences of various operating strategies have become feasible because of the detailed and quantitative nature of the mechanism-based kinetic networks reported here for the first time.
\end{abstract}

\section{Introduction}

The oxidative coupling of methane (OCM) involves the conversion of $\mathrm{CH}_{4}-\mathrm{O}_{2}$ mixtures to higher hydrocarbons ${ }^{1,2}$ and benefits from the avoidance of sequential steps required in indirect routes involving $\mathrm{CH}_{4}$ reforming and Fischer-Tropsch synthesis, ${ }^{3}$ while producing light alkenes, which cannot be formed via these indirect routes. Previous studies have addressed the synthesis of catalysts with improved $\mathrm{C}_{2}$ yields and selectivities where $\mathrm{Mn} / \mathrm{Na}_{2} \mathrm{WO}_{4} / \mathrm{SiO}_{2}$ catalysts ${ }^{4-7}$ have achieved among the highest reported $\mathrm{C}_{2}$ yields $26 \%$.,

OCM reactions involve the catalytic formation of methyl groups, ${ }^{9,10}$ which desorb as free radicals $\left(\mathrm{CH}_{3}{ }^{\circ}\right)$ that ultimately react via predominantly homogeneous pathways. Recombination of $\mathrm{CH}_{3}$ radicals in the gas phase forms $\mathrm{C}_{2} \mathrm{H}_{6}$ and subsequent dehydrogenation steps convert $\mathrm{C}_{2} \mathrm{H}_{6}$ to $\mathrm{C}_{2} \mathrm{H}_{4} \cdot{ }^{11} \mathrm{CO}_{x}(\mathrm{CO}$ and $\mathrm{CO}_{2}$ ) forms via catalytic and homogeneous primary and secondary pathways. Homogeneous pathways can also form $\mathrm{C}_{3+}$ hydrocarbons, which contain weaker $\mathrm{C}-\mathrm{H}$ bonds that favor their subsequent conversion to $\mathrm{CO}_{x}{ }^{12,13}$ Selectivities and yields depend on the identity and dynamics of specific elementary steps

* Corresponding author. Tel: 1-510-642-9673. Fax: 1-510-642-4778. E-mail: iglesia@berkeley.edu.

Current address: Department of Chemical System Engineering, The University of Tokyo, 7-3-1 Hongo Bunkyoku, Tokyo, 113-8656 Japan.

\section{SCHEME 1: Reaction Pathway for Oxidative Coupling} of Methane

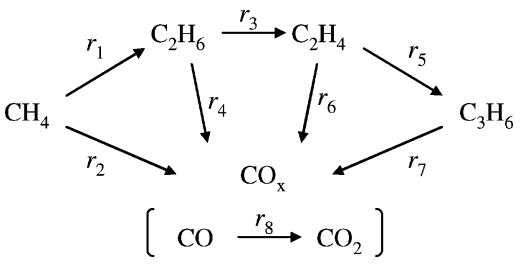

involved in these primary and secondary reactions. The details of such kinetic networks remain incomplete; yet, they are essential to describe these reactions in terms of their rate constants and pressure dependences and to define and exploit the specific contributions and kinetic coupling of surfacecatalyzed and gas phase reactions.

$\mathrm{C}_{2}$ selectivities typically decrease as $\mathrm{CH}_{4}$ conversion increases because primary $\mathrm{C}_{2}$ products oxidize to $\mathrm{CO}_{x}$ products favored by thermodynamics. Such sequential pathways (Scheme 1) account for the inherently limited yield of OCM processes. ${ }^{12-16}$ $\mathrm{CH}_{4}$ reacts first to form $\mathrm{C}_{2} \mathrm{H}_{6}$ and undesired $\mathrm{CO}_{x}$ byproducts via surface-catalyzed and homogeneous pathways, the rates of which depend on the relevant rate constants $\left(k_{1}, k_{2}\right.$; Scheme 1$)$, the reactant pressures $\left(\mathrm{CH}_{4}, \mathrm{O}_{2}\right)$, and the concentration of 
reaction products $\left(\mathrm{C}_{2} \mathrm{H}_{6}, \mathrm{C}_{2} \mathrm{H}_{4}, \mathrm{CO}_{x}, \mathrm{H}_{2} \mathrm{O}\right)$ prevalent at conversions required for practical OCM applications. $\mathrm{C}_{2}$ products are favored by high $\mathrm{CH}_{3}$ radical concentrations because their recombination is a bimolecular event, while competing oxidation pathways are proportional to $\mathrm{CH}_{3}$ concentration because they involve reactions with $\mathrm{O}_{2}$-derived species. $\mathrm{CH}_{3}$ oxidation depends on $\mathrm{O}_{2}$ concentrations, while $\mathrm{CH}_{3}$ recombination rates are independent of $\mathrm{O}_{2}$ pressure. Attainable $\mathrm{C}_{2}+$ yields depend sensitively on the relative rates of secondary reactions of $\mathrm{C}_{2}$ and $\mathrm{C}_{3+}$ products $\left(r_{3}-r_{7}\right.$; Scheme 1$)$ and of primary $\mathrm{CH}_{4}$ activation steps $\left(r_{1}\right)$. These secondary reactions involve the activation of $\mathrm{C}-\mathrm{H}$ bonds to form the various radical intermediates $\left(\mathrm{C}_{2} \mathrm{H}_{5}, \mathrm{C}_{2} \mathrm{H}_{3}\right.$, etc. $)$ via homolytic pathways similar in nature to those involved in $\mathrm{CH}_{4}$ activation. ${ }^{9,11}$ As a result, the relative rates of these reactions and the concomitant attainable maximum $\mathrm{C}_{2}$ yields are essentially dictated by the relative $\mathrm{C}-\mathrm{H}$ bond energies among the hydrocarbons involved in OCM. ${ }^{17}$

We report here rigorous kinetic and isotopic assessments of primary and secondary OCM pathways and their elementary steps. We also provide evidence for previously unrecognized effects of $\mathrm{H}_{2} \mathrm{O}$ on the relative rates of these steps and confirm the kinetic irrelevance of the other OCM products $\left(\mathrm{C}_{2} \mathrm{H}_{6}, \mathrm{C}_{2} \mathrm{H}_{4}\right.$, $\mathrm{CO}_{x}$ ) in $\mathrm{C}-\mathrm{H}$ bond activation of $\mathrm{CH}_{4}$ reactants. Specifically, we show that $\mathrm{H}_{2} \mathrm{O}$-derived gas phase $\mathrm{OH}$ radicals activate $\mathrm{C}-\mathrm{H}$ bonds in $\mathrm{CH}_{4}$ and $\mathrm{C}_{2} \mathrm{H}_{6}$ with less sensitivity to their respective $\mathrm{C}-\mathrm{H}$ bonds energies. We also find that the preponderance of $\mathrm{OH}-$ mediated homogeneous pathways (via intervening surface activation of $\mathrm{H}_{2} \mathrm{O}$ ) ameliorates $\mathrm{C}_{2} \mathrm{H}_{4}$ combustion routes favored by the preferential binding of alkenes $\left(\mathrm{C}_{2} \mathrm{H}_{4}, \mathrm{C}_{3} \mathrm{H}_{6}\right)$ on oxide surfaces. As a result, these $\mathrm{OH}$-mediated pathways lead to higher $\mathrm{C}_{2}$ selectivities and yields than are attainable with anhydrous reactants. These data, taken together with simulations using rigorous kinetic models, provide evidence for the relevance and consequences of quasi-equilibrated surface-catalyzed formation of reactive $\mathrm{OH}$ radicals from $\mathrm{O}_{2}-\mathrm{H}_{2} \mathrm{O}$ reactants. The resulting $\mathrm{OH}$-mediated pathways become the predominant route for OCM reactions as conversion increases or as $\mathrm{H}_{2} \mathrm{O}$ is added to $\mathrm{CH}_{4}-\mathrm{O}_{2}$ reactant streams; these pathways lead to limiting yields higher than $\mathrm{C}-\mathrm{H}$ activation routes that prevail under anhydrous conditions and are mediated exclusively by surface oxygen species at catalytic surfaces.

We have reported preliminary evidence for these selectivity improvements from $\mathrm{OH}$-mediated pathways in a previous short communication. ${ }^{18}$ The formation of $\mathrm{OH}$ radicals from $\mathrm{O}_{2}-\mathrm{H}_{2} \mathrm{O}$ mixtures has also been detected on basic oxides (e.g., $\mathrm{La}_{2} \mathrm{O}_{3}$, $\left.\mathrm{Nd}_{2} \mathrm{O}_{3}\right),{ }^{19,20}$ apparently on the same sites that activate $\mathrm{C}-\mathrm{H}$ bonds, a conclusion reached from the observed inhibition of $\mathrm{OH}$ formation by reactions of $\mathrm{CH}_{4}{ }^{21}$ These studies have also suggested that $\mathrm{OH}$ radicals would increase OCM rates, without experimental evidence, by activating $\mathrm{C}-\mathrm{H}$ bonds through homogeneous pathways, but also concluded that such pathways would not influence $\mathrm{C}_{2}$ selectivities or yields, because $\mathrm{OH}$ radicals would activate $\mathrm{C}-\mathrm{H}$ bonds in $\mathrm{CH}_{4}$ and OCM products with similar specificity. ${ }^{20}$ Two patents have disclosed positive effects of $\mathrm{H}_{2} \mathrm{O}$ on $\mathrm{CH}_{4}$ conversion rates and $\mathrm{C}_{2}$ selectivities on supported Mn-based catalysts, ${ }^{22,23}$ without mechanistic elucidation or speculation, and without any evidence for rigorous kinetic control or specific chemical effects of $\mathrm{H}_{2} \mathrm{O}$ (instead of concomitant and unintended changes in mass or heat transfer rates).

We show here that $\mathrm{OH}$ radicals react with $\mathrm{C}-\mathrm{H}$ bonds with less sensitivity to the $\mathrm{C}-\mathrm{H}$ bond strengths in $\mathrm{CH}_{4}$ and $\mathrm{C}_{2} \mathrm{H}_{6}$ than surface oxygens and with much lower reactivity for $\mathrm{C}_{2} \mathrm{H}_{4}$ than routes mediated by surfaces. Rate constants for surfacemediated pathways, measured under $\mathrm{H}_{2} \mathrm{O}$-free conditions, predict
$\mathrm{C}_{2}$ yields much lower than attained in practice, illustrating the essential role of $\mathrm{OH}$-mediated pathways, even without intentional addition of $\mathrm{H}_{2} \mathrm{O}$ to $\mathrm{CH}_{4}-\mathrm{O}_{2}$ reactants. In contrast, kinetic models that embed both surface-catalyzed and $\mathrm{OH}$-mediated steps and their rate constants accurately describe measured $\mathrm{C}_{2}$ synthesis rates, yields, and selectivities. We report the kinetic effects of $\mathrm{O}_{2}$ pressure on OCM rates, selectivities, and yields and their implications for staged $\mathrm{O}_{2}$ injection strategies ${ }^{15,24}$ that aim to maintain low $\mathrm{O}_{2}$ pressures while providing stoichiometric amounts of $\mathrm{O}_{2}$. Such strategies become effective in improving $\mathrm{C}_{2}$ yields only when $\mathrm{C}_{2}$ oxidation rates $\left(r_{4}, r_{6}, r_{7}\right)$ are more sensitive to $\mathrm{O}_{2}$ pressure than $\mathrm{CH}_{4}$ activation rates $\left(r_{1}\right)$. We find that $\mathrm{O}_{2}$ pressure effects are similar for activation of reactants $\left(\mathrm{CH}_{4}\right)$ and products $\left(\mathrm{C}_{2} \mathrm{H}_{6}, \mathrm{C}_{2} \mathrm{H}_{4}\right)$; thus, staging and membrane ${ }^{25}$ strategies are unlikely to improve $\mathrm{C}_{2}$ yields, but may be useful to control local exotherms or to extract $\mathrm{O}_{2}$ from air during OCM. The concepts reported here, as well as their catalytic consequences, are applicable in general to attain high OCM yields.

\section{Experimental Section}

Catalysts were prepared using procedures reported previously. ${ }^{6} \mathrm{SiO}_{2}$ (Davison Chemicals, Silica Gel grade 57) was sieved to retain aggregates $0.10-0.85 \mathrm{~mm}$ in diameter. These aggregates were contacted with aqueous $\mathrm{Mn}\left(\mathrm{NO}_{3}\right)_{2}$ solutions (50 wt \%; Strem Chemicals, $2 \mathrm{~cm}^{3} / \mathrm{g}-\mathrm{SiO}_{2}$ ) for $2 \mathrm{~h}$ and treated in ambient air at $403 \mathrm{~K}$ for $5 \mathrm{~h}^{6}{ }^{6}$ The samples were then stirred in an aqueous solution of $\mathrm{Na}_{2} \mathrm{WO}_{4} \cdot 2 \mathrm{H}_{2} \mathrm{O}$ (Sigma-Aldrich, 99\%, $2 \mathrm{~cm}^{3} / \mathrm{g}-\mathrm{SiO}_{2}$ ) to give $2 \mathrm{wt} \% \mathrm{Mn}$ and $5 \mathrm{wt} \% \mathrm{Na}_{2} \mathrm{WO}_{4}$. Finally, the samples were treated in ambient air at $403 \mathrm{~K}$ for $5 \mathrm{~h}$ and in flowing dry air (Praxair, UHP, $10 \mathrm{~g}$-cat, $0.167 \mathrm{~cm}^{3} \mathrm{~s}^{-1}$ ) by increasing the temperature at $0.033 \mathrm{~K} \mathrm{~s}^{-1}$ and holding at 1173 $\mathrm{K}$ for $8 \mathrm{~h}$. The samples were sieved again before use to retain aggregates with a narrower size range $(0.25-0.35 \mathrm{~mm})$.

OCM rates and selectivities were measured in flow and recirculating batch reactors using $\mathrm{U}$-shaped quartz reactor cells (4 mm I.D.). Catalysts $(0.02-0.05 \mathrm{~g})$ were diluted with inert $\mathrm{SiO}_{2}$ particles $(0.5 \mathrm{~g}$; Fluka, $0.25-0.35 \mathrm{~mm})$ and held onto quartz wool. The temperature was controlled using a Watlow controller (Series 982) and a resistively heated furnace and was measured with a K-type thermocouple contacting the outer surface of the reactor. $\mathrm{CH}_{4}$ (Praxair, 99.999\%) and $\mathrm{O}_{2}$ (Praxair, 99.999\%) were introduced with $\mathrm{He}$ (Praxair, 99.999\%) as a diluent using mass flow controllers (Porter Inc. model 201). In batch experiments, the recirculation volume $\left(275-650 \mathrm{~cm}^{3}\right)$ was evacuated to $<0.1 \mathrm{~Pa}$ before introducing reactants, which were continuously circulated using a graphite gear pump (Micropump, model 182-000, >2.5 $\mathrm{cm}^{3} \mathrm{~s}^{-1}$ ). Water was removed as it was formed in some experiments using a dry ice/acetone cold trap held within the recirculating line. Reactant and product concentrations were measured with a HP5890 gas chromatograph using a Carbosieve SII packed column (Supelco, $3.2 \mathrm{~mm} \times$ $2 \mathrm{~m}$ ) with a thermal conductivity detector and a HP-PLOT Q capillary column (Agilent Technology Inc., $0.32 \mathrm{~mm} \times 30 \mathrm{~m}$ ) with a flame ionization detector. Differential rates were obtained from time-derivatives of hydrocarbon concentration profiles in batch reactors, after regressing concentration-time data to a sixth-order polynomial. Selectivities and yields are reported on a carbon basis as cumulative integral values.

$\mathrm{CD}_{4}$ (Isotec, 99 at \% D), $\mathrm{D}_{2} \mathrm{O}$ (Cambridge Isotope Laboratories, Inc., 99.9\%), and ${ }^{18} \mathrm{O}_{2}$ (Isotec, 99 at $\%{ }^{18} \mathrm{O}$ ) were used to measure kinetic isotope effects and isotopic scrambling dynamics. Isotopic tracer studies were carried out using labeled ${ }^{13} \mathrm{CH}_{4}$ (Isotec, 99 at $\%{ }^{13} \mathrm{C}$ ) in the presence of ${ }^{12} \mathrm{C}_{2} \mathrm{H}_{6}$ (Praxair, chemical purity $99.999 \%$ ), ${ }^{12} \mathrm{C}_{2} \mathrm{H}_{4}$ (Praxair, chemical purity 

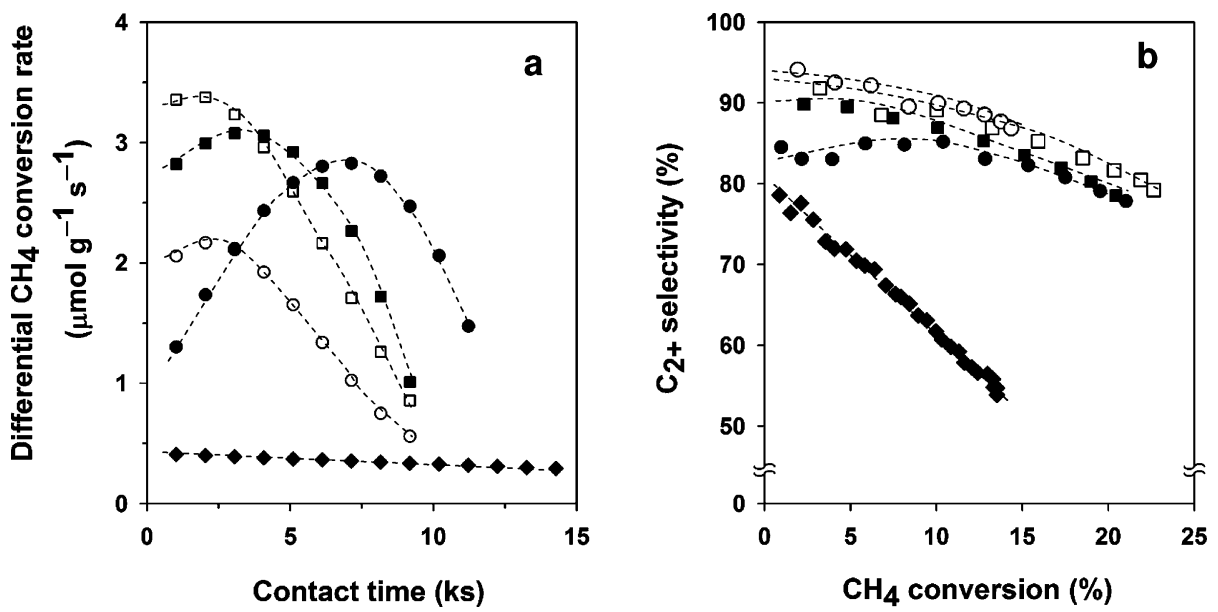

Figure 1. Differential $\mathrm{CH}_{4}$ conversion rate as a function of contact time (a) and $\mathrm{C}_{2+}$ selectivity as a function of $\mathrm{CH}_{4}$ conversion (b) measured in a recirculating reactor $\left(0.02 \mathrm{~g}, 1073 \mathrm{~K}\right.$, volume: $275-650 \mathrm{~cm}^{3}, 10.7 \mathrm{kPa} \mathrm{CH}_{4}, 101 \mathrm{kPa}$ total pressure, balance $\mathrm{He},(\diamond) 1.8 \mathrm{kPa} \mathrm{O}, \mathrm{H}_{2} \mathrm{O}$ removed; ${ }^{18}$

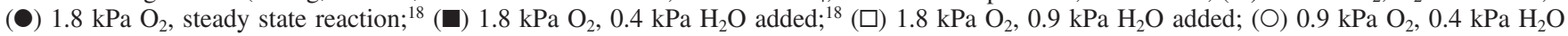
added).

99.999\%), or $5 \%{ }^{12} \mathrm{C}_{3} \mathrm{H}_{6} / \mathrm{He}$ (Praxair). Labeled ${ }^{13} \mathrm{CO}$ (Isotec, $99 \%{ }^{13} \mathrm{C}$ ) was used to measure $\mathrm{CO}$ oxidation rates during OCM. These isotopic studies used the gas chromatograph described above and also a HP5890 GC equipped with a mass selective detector (HP 5972) connected to a HP-PLOT Q capillary column.

Simulations were carried out using ChemKin $\operatorname{codes}^{26}$ and reported gas-phase rate constants and thermodynamics. ${ }^{14}$ This homogeneous kinetic model contains 447 reversible elementary chemical reactions and 115 species.

The surface area of the $\mathrm{Mn} / \mathrm{Na}_{2} \mathrm{WO}_{4} / \mathrm{SiO}_{2}$ sample, after treatment in dry flowing air at $1173 \mathrm{~K}$ for $8 \mathrm{~h}$, was $1.3 \mathrm{~m}^{2} \mathrm{~g}^{-1}$, as determined from $\mathrm{N}_{2}$ physisorption at its normal boiling point using the BET formalism. ${ }^{27}$ This treatment sinters samples to an extent that renders them stable against further changes in structure or surface area during subsequent catalytic tests, as reported earlier. ${ }^{7}$ No detectable changes in OCM rates or selectivities were detected for $>80 \mathrm{ks}$ after such thermal treatments.

\section{Results and Discussion}

3.1. Effects of $\mathrm{H}_{2} \mathrm{O}$ Pressure on $\mathbf{C H}_{4}$ Conversion Rates and $\mathbf{C}_{2+}$ Selectivity. Figure 1, panels a and b, shows differential $\mathrm{CH}_{4}$ conversion rates per gram of catalyst; from time derivatives of concentration profiles as a function of contact time and $\mathrm{C}_{2+}$ selectivities as a function of $\mathrm{CH}_{4}$ conversion, respectively, on $\mathrm{Mn} / \mathrm{Na}_{2} \mathrm{WO}_{4} / \mathrm{SiO}_{2}$ catalysts in a gradientless batch reactor at $1073 \mathrm{~K}$. At $10.7 \mathrm{kPa} \mathrm{CH}_{4}$ and $1.8 \mathrm{kPa} \mathrm{O}_{2}$ (filled circles; "steady state reaction"), Figure 1a shows that $\mathrm{CH}_{4}$ conversion rates initially increased with contact time and then decreased as $\mathrm{O}_{2}$ coreactants were depleted in all experiments for which reactants and products were kept in contact with the catalyst. $\mathrm{C}_{2}$ selectivities remained nearly constant up to $\sim 10 \% \mathrm{CH}_{4}$ conversion and subsequently decreased gradually as conversion increased with contact time (Figure 1b).

This enhancement in $\mathrm{CH}_{4}$ conversion rate with increasing conversion (and contact time) was not caused by local high temperatures as a result of exothermic $\mathrm{CH}_{4}$ oxidation reactions, ${ }^{7}$ because varying catalyst dilution with quartz particles $(0: 1$ to 50:1 quartz to catalyst ratio) did not detectably influence measured rates. The recirculation strategy used here minimizes the amount of energy released per pass compared with commonly used single-pass flow reactors. ${ }^{28,29}$ Changes in catalyst structure or accessibility also do not account for the observed increase in rates, because these trends were observed again when reactor contents were replaced with fresh $\mathrm{CH}_{4} / \mathrm{O}_{2}$ reactants directly after one of these experiments and without intervening thermal treatments. We conclude, therefore, that these "activation" or "autocatalytic" trends are kinetic in origin; they must reflect either a negative kinetic order in $\mathrm{CH}_{4}$ or $\mathrm{O}_{2}$ reactants, which are depleted with contact time, or positive effects by one or more of the OCM products $\left(\mathrm{C}_{2} \mathrm{H}_{6}, \mathrm{C}_{2} \mathrm{H}_{4}, \mathrm{CO}, \mathrm{CO}_{2}\right.$, and $\left.\mathrm{H}_{2} \mathrm{O}\right)$, which increase in concentration as conversion increases with contact time.

We observe in independent experiments an increase in $\mathrm{CH}_{4}$ conversion rate with increasing $\mathrm{CH}_{4}$ and $\mathrm{O}_{2}$ pressures in the initial reactant stream. We do not find, however, any detectable effects of ethene or ethane on rates or selectivities (vide infra). Thus, negative kinetic orders in reactants or positive effects of $\mathrm{C}_{2}$ products cannot account for the observed increase in $\mathrm{CH}_{4}$ conversion rates with contact time. As we have shown earlier, ${ }^{18}$ $\mathrm{H}_{2} \mathrm{O}$ may instead affect $\mathrm{CH}_{4}$ reactions, consistent with the data in Figure 1, panels a and $b$, in which $\mathrm{H}_{2} \mathrm{O}$ was either continuously removed as it formed in OCM reactions (labeled " $\mathrm{H}_{2} \mathrm{O}$ removed") or added to the initial reactant mixtures (labeled " $\mathrm{H}_{2} \mathrm{O}$ added").

The continuous removal of $\mathrm{H}_{2} \mathrm{O}$ during OCM reactions led to $\mathrm{CH}_{4}$ conversion rates that decreased monotonically with increasing contact time and $\mathrm{CH}_{4}$ conversion, as expected from the gradual depletion of reactants and the positive OCM kinetic orders in $\mathrm{CH}_{4}$ and $\mathrm{O}_{2}$ pressures (filled diamonds; Figure 1a). $\mathrm{C}_{2}$ selectivities decreased with contact time more strongly when $\mathrm{H}_{2} \mathrm{O}$ was removed than when it was allowed to accumulate during reaction or when it was added initially together with reactants (Figure 1b). $\mathrm{H}_{2} \mathrm{O}$ addition $(0.4 \mathrm{kPa})$ to $\mathrm{CH}_{4}-\mathrm{O}_{2}$ reactants led to higher initial $\mathrm{CH}_{4}$ conversion rates than for anhydrous reactants and to a subsequent decrease in rates as reactants were depleted (filled squares; Figure 1a). Higher $\mathrm{H}_{2} \mathrm{O}$ pressures $(0.9 \mathrm{kPa})$ led to even higher initial rates (open squares; Figure 1a). $\mathrm{H}_{2} \mathrm{O}$ addition also increased initial $\mathrm{C}_{2}$ selectivities (Figure 1b). These effects of water became weaker as $\mathrm{CH}_{4}$ conversion increased, because $\mathrm{H}_{2} \mathrm{O}$ concentrations increased to similar levels as conversion increased, even with anhydrous feeds.

An earlier study proposed that $\mathrm{OH}$ radicals formed from $\mathrm{H}_{2} \mathrm{O}$ could increase $\mathrm{CH}_{4}$ activation rates, but not $\mathrm{C}_{2}$ selectivities, 
during OCM reactions..$^{20}$ Our results show that $\mathrm{H}_{2} \mathrm{O}$ markedly influences both rates and selectivities. These effects are discussed next in the context of the kinetic response of the various steps to $\mathrm{CH}_{4}$ and $\mathrm{O}_{2}$ pressures in the absence of $\mathrm{H}_{2} \mathrm{O}$. We then address the specific effects of $\mathrm{H}_{2} \mathrm{O}$ in the steps required for the activation of $\mathrm{CH}_{4}, \mathrm{C}_{2} \mathrm{H}_{6}$, and $\mathrm{C}_{2} \mathrm{H}_{4}$ (Scheme 1) and report rate constants for surface-mediated and $\mathrm{H}_{2} \mathrm{O}$-mediated reaction pathways using isotopic tracing methods. We also report kinetic isotope effects and scrambling rates that probe the nature and reversibility of the relevant elementary steps.

3.2. Rate Equations and Elementary Steps for $\mathrm{CH}_{4} / \mathbf{O}_{2}$ Reactions under Anhydrous Conditions. The kinetic response of $\mathrm{CH}_{4}$ conversion rates to $\mathrm{CH}_{4}$ and $\mathrm{O}_{2}$ pressures was measured on $\mathrm{Mn} / \mathrm{Na}_{2} \mathrm{WO}_{4} / \mathrm{SiO}_{2}$ at $1073 \mathrm{~K}$ in a plug-flow reactor by varying space velocity and inlet concentrations. Rates and selectivities were extrapolated to zero $\mathrm{CH}_{4}$ conversion to measure kinetic data under strictly anhydrous conditions (using five data points at $\mathrm{CH}_{4}$ conversions below 5\%). No reaction products were detected in the absence of a catalyst at these reaction conditions.

Measured $\mathrm{CH}_{4}$ conversion rates $\left(r_{\mathrm{CH}_{4}}\right)$ were proportional to $P_{\mathrm{CH}_{4}} P_{\mathrm{O}_{2}}^{1 / 2}$, as previously reported; ${ }^{6}$ these data are consistent with quasi-equilibrated dissociative $\mathrm{O}_{2}$ chemisorption on vicinal surface vacancies $(*)$ to form reactive $\mathrm{O}_{\mathrm{s}}{ }^{*}$ species (step 1) and with kinetically-relevant steps in which these $\mathrm{O}_{\mathrm{s}}^{*}$ species abstract $\mathrm{H}$-atoms from $\mathrm{CH}_{4}$ to form adsorbed $\mathrm{OH}^{*}$ and gasphase methyl radicals (step 2). This catalytic sequence is then completed via quasi-equilibrated recombination of $\mathrm{OH}^{*}$ to form $\mathrm{H}_{2} \mathrm{O}$ and surface vacancies (step 3):

$$
\begin{gathered}
\mathrm{O}_{2}+2 * \stackrel{K_{\mathrm{O}_{2}}}{\rightleftarrows} 2 \mathrm{O}_{\mathrm{s}}^{*} \\
\mathrm{CH}_{4}+\mathrm{O}_{\mathrm{s}} * \stackrel{k_{\mathrm{CH}_{4}}^{\prime}}{\longrightarrow} \mathrm{CH}_{3} \cdot+\mathrm{OH}^{*} \\
2 \mathrm{OH}^{*} \stackrel{\mathrm{O}}{\rightleftarrows} \mathrm{H}_{2} \mathrm{O}+\mathrm{O}_{\mathrm{s}}^{*}+*
\end{gathered}
$$

Kinetic data cannot be used to determine whether $\mathrm{H}$ abstraction occurs from gas phase $\mathrm{CH}_{4}$ or from $\mathrm{CH}_{4}$ weakly adsorbed at low coverages in step 2, because both predict rates proportional to $\mathrm{CH}_{4}$ pressure. These steps and the pseudosteady state assumption for all adsorbed species lead to $\mathrm{CH}_{4}$ conversion rates given by

$$
r_{\mathrm{CH}_{4}}=k_{\mathrm{CH}_{4}}^{\prime} P_{\mathrm{CH}_{4}} \frac{\sqrt{K_{\mathrm{O}_{2}} P_{\mathrm{O}_{2}}}}{1+\sqrt{K_{\mathrm{O}_{2}} P_{\mathrm{O}_{2}}}}
$$

at conditions where products are present at low concentrations and their kinetic effects are negligible. Figure 2 shows $\left(P_{\mathrm{CH}_{4}} /\right.$ $r_{\mathrm{CH}_{4}}$ ) ratios as a function of $P_{\mathrm{O}_{2}}^{-1 / 2}$. The identical linear correlations at these two $\mathrm{CH}_{4}$ partial pressures are consistent with eq 4 . The value of $K_{\mathrm{O}_{2}}$ obtained from these data was very small $(0.005 \pm$ $\left.0.01 \mathrm{kPa}^{-1}\right)$, indicating that $\mathrm{O}_{\mathrm{s}} *$ coverages are very small during OCM catalysis. Hence, eq 4 becomes

$$
r_{\mathrm{CH}_{4}}=k_{\mathrm{CH}_{4}}^{\prime} K_{\mathrm{O}_{2}}^{1 / 2} P_{\mathrm{CH}_{4}} P_{\mathrm{O}_{2}}^{1 / 2}
$$

The small $K_{\mathrm{O}_{2}}$ value reflects the weakly bound nature of active oxygen species (e.g., $\mathrm{O}^{-}$or $\mathrm{O}_{2}{ }^{2-}$ species ${ }^{9,31}$ ).

The temperature dependence of $\mathrm{CH}_{4}$ conversion rate constants under anhydrous conditions $\left(k^{\prime}=k_{\mathrm{CH}_{4}}^{\prime} K_{\mathrm{O}_{2}}^{1 / 2}\right.$ in Figure 3; 993-1123

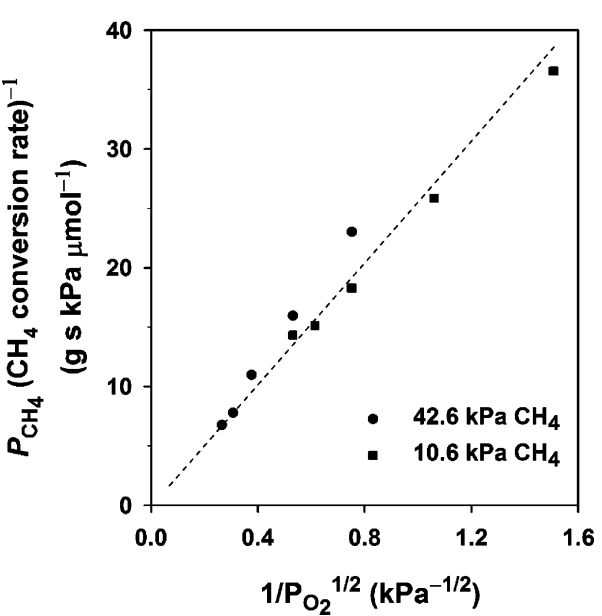

Figure 2. Effects of $\mathrm{O}_{2}$ partial pressure on $\mathrm{CH}_{4}$ conversion rate. The rates are divided by $\mathrm{CH}_{4}$ partial pressure and the reciprocal plots are shown. All rates are taken by extrapolation to zero conversion from the results at varied conversions $(0.05 \mathrm{~g}, 1073 \mathrm{~K}, 101 \mathrm{kPa}$ total pressure, balance $\mathrm{He}$ ).

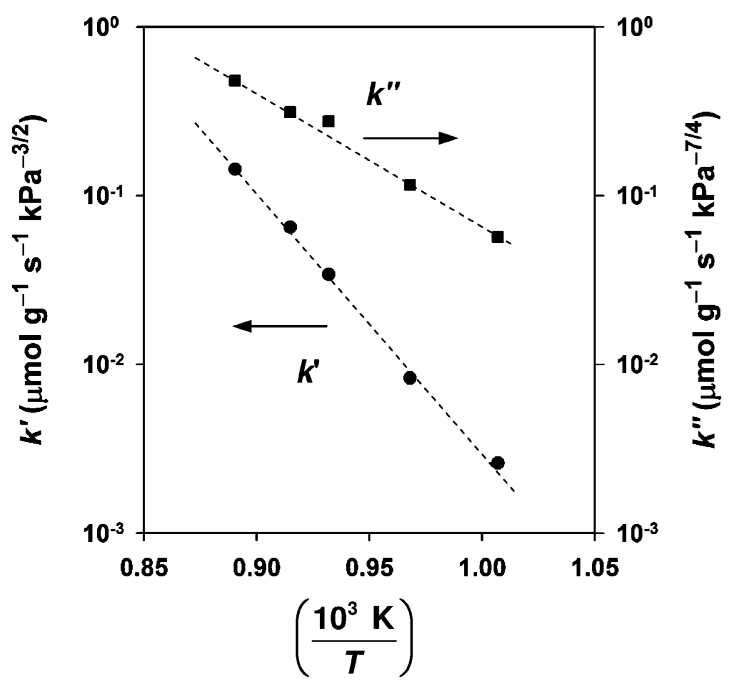

Figure 3. Arrhenius plots for rate constants in the rate expression: $r_{\mathrm{CH}_{4}}=k^{\prime} P_{\mathrm{CH}_{4}} P_{\mathrm{O}_{2}}^{1 / 2}+k^{\prime \prime} P_{\mathrm{CH}_{4}} P_{\mathrm{O}_{2}}^{1 / 4} P_{\mathrm{H}_{2} \mathrm{O}}^{1 / 2}$ (eq 19) $(0.02 \mathrm{~g}, 1073 \mathrm{~K}$, volume: $550 \mathrm{~cm}^{3}, 10.7 \mathrm{kPa} \mathrm{CH}_{4}, 1.8 \mathrm{kPa} \mathrm{O}_{2}, 101 \mathrm{kPa}$ total pressure, balance $\mathrm{He})$.

K) gives an apparent activation energy $\left(E_{\text {app }}\right)$ of $290 \pm 8 \mathrm{~kJ}$ $\mathrm{mol}^{-1}$, consistent with previously reported values $(280 \mathrm{~kJ}$ $\left.\mathrm{mol}^{-1}\right){ }^{6}$ This activation energy reflects the combined contributions from the activation barrier for $\mathrm{H}$-abstraction in step $2\left(E_{\mathrm{a}, \mathrm{O}^{*}}\right)$ and the enthalpy for dissociative $\mathrm{O}_{2}$ adsorption in step $1\left(\Delta H_{\mathrm{O}_{2}}\right)$

$$
E_{\mathrm{app}}^{\prime}=E_{\mathrm{a}, \mathrm{O} *}+\frac{1}{2} \Delta H_{\mathrm{O}_{2}}
$$

If $\mathrm{O}_{2}(\mathrm{~g})$ loses all degrees of freedom upon adsorption to form $\mathrm{O}_{\mathrm{s}}{ }^{*}$ (step 1), the measured $K_{\mathrm{O}_{2}}\left(0.005 \mathrm{kPa}^{-1}\right.$ at $\left.1073 \mathrm{~K}\right)$ corresponds to a $\Delta H_{\mathrm{O}_{2}}$ value of $-176 \mathrm{~kJ} \mathrm{~mol}^{-1}$. Equation 6 and measured $E_{\text {app }}$ values $\left(290 \pm 8 \mathrm{~kJ} \mathrm{~mol}^{-1}\right)$ then give an activation energy for step $2\left(E_{\mathrm{a}, \mathrm{O}^{*}}\right)$ of $378 \mathrm{~kJ} \mathrm{~mol}^{-1}$. This energy is similar to that required to dissociate $\mathrm{C}-\mathrm{H}$ bonds in $\mathrm{CH}_{4}(439$ $\left.\mathrm{kJ} \mathrm{mol}^{-1}\right)^{32}$ without any concerted interactions with surfaces or other molecules; it is indicative of a late transition state along the reaction coordinate. In practice, $\mathrm{O}_{\mathrm{s}} *$ is expected to retain some translational freedom (leading to weaker $\mathrm{M}-\mathrm{O}$ bonds and less negative $\Delta H_{\mathrm{O}_{2}}$ values), because the strength of $\mathrm{O}_{\mathrm{s}} *$ binding allow some surface migration at typical OCM reaction temperatures. $\mathrm{O}_{2}$ adsorption processes, however, must be exothermic 
TABLE 1: Kinetic Isotope Effects Measured in a Recirculating Reactor $\left(0.02 \mathrm{~g}, 1073 \mathrm{~K}\right.$, Unit Volume $550 \mathrm{~cm}^{3}$, $10.7 \mathrm{kPa} \mathrm{CH}_{4}$ or $\mathrm{CD}_{4}, 0.4 \mathrm{kPa} \mathrm{H}_{2} \mathrm{O}$ or $\mathrm{D}_{2} \mathrm{O}$ (when Added), $101 \mathrm{kPa}$ Total Pressure, Balance $\mathrm{He}$ )

\begin{tabular}{ccc}
\hline rate ratio & $\mathrm{O}_{2}(\mathrm{kPa})$ & KIE \\
\hline $\mathrm{CH}_{4}-\mathrm{O}_{2} / \mathrm{CD}_{4}-\mathrm{O}_{2}$ & 3.5 & 1.29 \\
$\mathrm{CH}_{4}-\mathrm{O}_{2} / \mathrm{CD}_{4}-\mathrm{O}_{2}$ & 1.8 & 1.25 \\
$\mathrm{CH}_{4}-\mathrm{O}_{2} / \mathrm{CD}_{4}-\mathrm{O}_{2}$ & 0.9 & 1.24 \\
$\left(\mathrm{CH}_{4}-\mathrm{O}_{2}-\mathrm{H}_{2} \mathrm{O}\right) /\left(\mathrm{CD}_{4}-\mathrm{O}_{2}-\mathrm{H}_{2} \mathrm{O}\right)$ & 1.8 & 1.44 \\
{$\left[\left(\mathrm{CH}_{4}-\mathrm{O}_{2}-\mathrm{H}_{2} \mathrm{O}\right)-\left(\mathrm{CH}_{4}-\mathrm{O}_{2}\right)\right] /$} & 1.8 & 1.58 \\
{$\left[\left(\mathrm{CD}_{4}-\mathrm{O}_{2}-\mathrm{H}_{2} \mathrm{O}\right)-\left(\mathrm{CD}_{4}-\mathrm{O}_{2}\right)\right]$} & & \\
$\mathrm{CH}_{4}-\mathrm{O}_{2}-\mathrm{H}_{2} \mathrm{O} / \mathrm{CH}_{4}-\mathrm{O}_{2}-\mathrm{D}_{2} \mathrm{O}$ & 1.8 & 1.08
\end{tabular}

for them to occur, because of the concomitant entropy losses upon adsorption. Therefore, intrinsic $\mathrm{C}-\mathrm{H}$ bond activation barriers must be larger than those measured $\left(>290 \mathrm{~kJ} \mathrm{~mol}^{-1}\right)$. These data seem to indicate that the role of $\mathrm{O}_{\mathrm{s}}{ }^{*}$ is predominantly to scavenge $\mathrm{H}$ atoms by forming $\mathrm{OH}^{*}$ and that its role in stabilizing late transition states with significant radical character in the $\mathrm{CH}_{3}$ moiety is relatively small.

We have probed the kinetic relevance of $\mathrm{C}-\mathrm{H}$ bond activation steps by measuring kinetic isotope effects (KIE) for $\mathrm{CH}_{4} / \mathrm{O}_{2}$ and $\mathrm{CD}_{4} / \mathrm{O}_{2}$ reactants (Table 1 ). Rates were measured by extrapolation to zero conversion to ensure anhydrous conditions. Normal KIE values (1.24-1.29, Table 1) were found at all $\mathrm{O}_{2}$ pressures $(0.9-3.5 \mathrm{kPa})$, consistent with $\mathrm{C}-\mathrm{H}$ bond activation as the kinetically relevant step, as discussed in more detail in the Supporting Information.

The extent to which $\mathrm{C}-\mathrm{H}$ bond activation steps are reversible during OCM reactions was determined from the rate of formation of mixed $\mathrm{CH}_{x} \mathrm{D}_{(4-x)}(0<x<4)$ isotopomers (here used to denote molecules with different $x$ values) during reactions of $\mathrm{CH}_{4} / \mathrm{CD}_{4} / \mathrm{O}_{2}$ isotopic mixtures. The ratio of the isotopic scrambling rate to the chemical conversion rate was negligible $(\ll 1)$ (Figure 4 ); these data show that $\mathrm{C}-\mathrm{H}$ bond activation steps (step 2) are essentially irreversible during OCM reactions. $\mathrm{CH}_{x} \mathrm{D}_{(4-x)}$ isotopomers gradually formed with increasing contact time and $\mathrm{CH}_{4}$ conversion as a result of homogeneous $\mathrm{H}$-transfer reactions between $\mathrm{CH}_{3}{ }^{\bullet}$ and $\mathrm{CH}_{4}$ (or $\mathrm{C}_{2} \mathrm{H}_{6}$ ) (e.g., $\mathrm{CH}_{3}{ }^{\circ}+\mathrm{C}_{2} \mathrm{H}_{6}$ $\rightarrow \mathrm{CH}_{4}+\mathrm{C}_{2} \mathrm{H}_{5}{ }^{\circ}$ ).

The quasi-equilibrated nature of $\mathrm{O}_{2}$ dissociation steps (step 1) was confirmed from the rate of isotopic scrambling in dioxygen molecules during reactions of $\mathrm{CH}_{4} /{ }^{16} \mathrm{O}_{2} /{ }^{18} \mathrm{O}_{2}$ mixtures

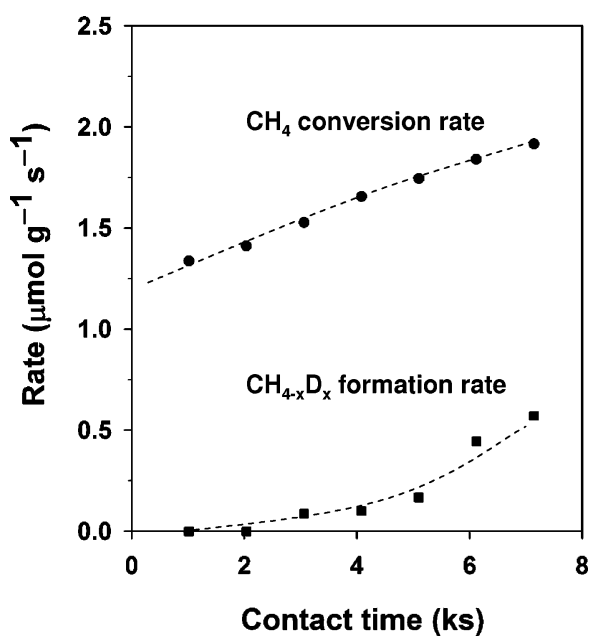

Figure 4. Methane chemical conversion and $\mathrm{CH}_{4} / \mathrm{CD}_{4}$ cross exchange rates during reaction of $\mathrm{CH}_{4} / \mathrm{CD}_{4} / \mathrm{O}_{2}$ mixture measured in a recirculating batch reactor $\left(0.02 \mathrm{~g}, 1073 \mathrm{~K}\right.$, volume: $550 \mathrm{~cm}^{3}, 5.3 \mathrm{kPa} \mathrm{CH}_{4}$ and $\mathrm{CD}_{4}$, $1.8 \mathrm{kPa} \mathrm{O}_{2}, 101 \mathrm{kPa}$ total pressure, balance $\mathrm{He}$ ).

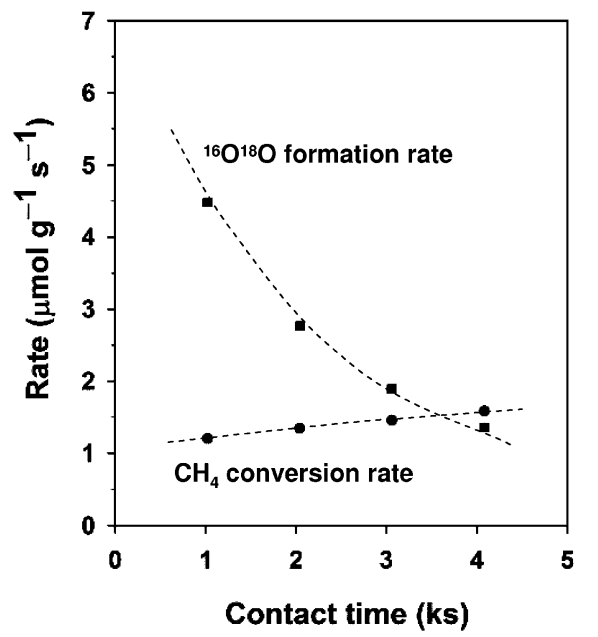

Figure 5. Methane chemical conversion rate and ${ }^{16} \mathrm{O}^{18} \mathrm{O}$ isotopomer formation rate during the reaction of $\mathrm{CH}_{4} /{ }^{16} \mathrm{O}_{2} /{ }^{18} \mathrm{O}_{2}$ mixture measured in a recirculating batch reactor $\left(0.02 \mathrm{~g}, 1073 \mathrm{~K}\right.$, volume $550 \mathrm{~cm}^{3}, 10.7$ $\mathrm{kPa} \mathrm{CH}, 0.9 \mathrm{kPa}{ }^{16} \mathrm{O}_{2}, 0.9 \mathrm{kPa}{ }^{18} \mathrm{O}_{2}, 101 \mathrm{kPa}$ total pressure, balance $\mathrm{He})$.

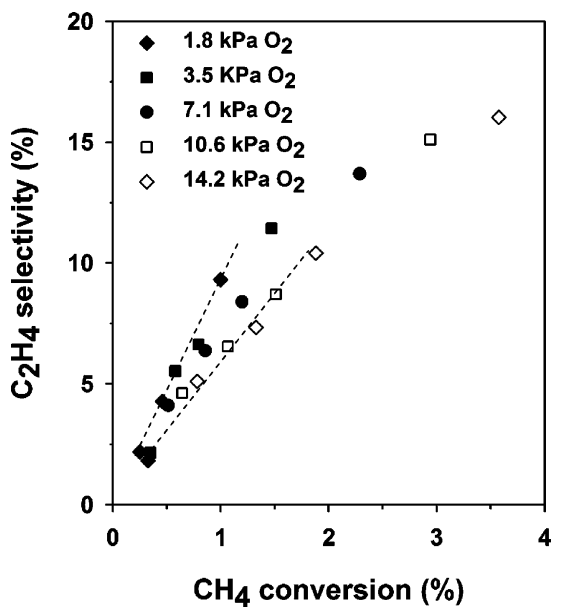

Figure 6. $\mathrm{C}_{2} \mathrm{H}_{4}$ selectivity as a function of $\mathrm{CH}_{4}$ conversion measured in a flow reactor $\left(0.05 \mathrm{~g}, 1073 \mathrm{~K}, \mathrm{CH}_{4} 42.6 \mathrm{kPa}, 101 \mathrm{kPa}\right.$ total pressure, balance $\mathrm{He}, 1.0-2.5 \mathrm{~cm}^{3} \mathrm{~s}^{-1}$ total flow rate). Dashed lines denote linear regressions of the results at low $\mathrm{CH}_{4}$ conversions $(<2 \%)$ for data of 1.8 and $14.2 \mathrm{kPaO}_{2}$.

(Figure 5). Rates extrapolated to zero conversion were $\sim 10$ times larger for ${ }^{16} \mathrm{O}^{18} \mathrm{O}$ isotopomers (via the reverse of step 1) than for $\mathrm{CH}_{4}$ chemical conversion (step 2). These data are consistent with fast and quasi-equilibrated $\mathrm{O}_{2}$ dissociation (eq 1). We note, however, that these relative rates differ by only a factor of $\sim 10$ and that the assumption of quasi-equilibrium may become inaccurate as $\mathrm{CH}_{4}$ pressure increases or $\mathrm{O}_{2}$ pressure decreases by commensurate factors, because these two molecules determine the rates at which $\mathrm{O}_{\mathrm{s}}{ }^{*}$ species react and form, respectively. The breakdown of the quasi-equilibrium assumption for $\mathrm{O}_{2}$ chemisorption as $\mathrm{O}_{2}$ is depleted with increasing conversion is addressed later (section 3.4).

3.3. Effects of Reactant Concentrations on OCM Selectivity under Anhydrous Conditions. We examine next product formation rates and selectivities from $\mathrm{CH}_{3}$ radicals, the species involved intermediates in OCM reactions and formed in step $2,{ }^{9,10}$ under anhydrous conditions. First, we examine whether $\mathrm{C}_{2} \mathrm{H}_{4}$ can be formed directly from $\mathrm{CH}_{4} / \mathrm{O}_{2}$ mixtures on $\mathrm{Mn}$ / $\mathrm{Na}_{2} \mathrm{WO}_{4} / \mathrm{SiO}_{2}$ at $1073 \mathrm{~K}$. Figure 6 shows $\mathrm{C}_{2} \mathrm{H}_{4}$ selectivities as a function of $\mathrm{CH}_{4}$ conversion at several $\mathrm{O}_{2}$ pressures $(1.8-14.2$ $\mathrm{kPa} ; 42.6 \mathrm{kPa} \mathrm{CH}_{4}$ ). Initial $\mathrm{C}_{2} \mathrm{H}_{4}$ selectivities (at zero conversion) 
are essentially zero, indicating that ethene forms only via dehydrogenation of primary $\mathrm{C}_{2} \mathrm{H}_{6}$ products, instead of directly from $\mathrm{CH}_{4}$ (or $\mathrm{CH}_{3}$ radicals). These data contradict previous proposals that $\mathrm{C}_{2} \mathrm{H}_{4}$ can form directly from $\mathrm{CH}_{4}$ via carbene intermediates. ${ }^{33}$ Very low conversions $(<1 \%)$ are essential to probe the identity of primary and secondary products because of the strong effects of $\mathrm{H}_{2} \mathrm{O}$ on OCM rates and $\mathrm{C}_{2}$ selectivities as $\mathrm{CH}_{4}$ conversion increases with residence time. Our rigorous extrapolation to low conversions shows unequivocally that $\mathrm{C}_{2} \mathrm{H}_{6}$, $\mathrm{CO}$ and $\mathrm{CO}_{2}$ are the only primary products formed from $\mathrm{CH}_{4} /$ $\mathrm{O}_{2}$ reactants.

Figure $7 \mathrm{a}-\mathrm{c}$ shows $\mathrm{C}_{2} \mathrm{H}_{6}, \mathrm{CO}$, and $\mathrm{CO}_{2}$ formation rates (extrapolated to zero conversion) as a function of $\mathrm{CH}_{4}$ pressure in a flow reactor. These rates rigorously reflect the formation of each product directly from $\mathrm{CH}_{4} / \mathrm{O}_{2}$ reactants. $\mathrm{CH}_{3}$ radicals recombine to form $\mathrm{C}_{2} \mathrm{H}_{6}$ (step 7), but may also react to give $\mathrm{CO}$ and $\mathrm{CO}_{2} ; \mathrm{CO}_{x}$ also shows selectivity trends with residence time consistent with primary products, even though they form via $\mathrm{CH}_{3}{ }^{\circ}$, because these $\mathrm{CH}_{3}{ }^{\circ}$ reactive intermediates are very reactive during OCM reactions and are present at their pseudosteady-state concentrations. Panels $\mathrm{b}$ and $\mathrm{c}$ in Figure 7 (and data from $\mathrm{O}_{2}$ pressure variations shown in Figure $\mathrm{S} 1$ in the Supporting Information) show that $\mathrm{O}_{2}$ pressures influence $\mathrm{CO}$ formation rates more strongly than $\mathrm{CO}_{2}$ formation rates, suggesting that $\mathrm{CO}_{2}$ forms predominantly via reactions of $\mathrm{CH}_{3}{ }^{\circ}$ with $\mathrm{O}^{*}\left(\sim \mathrm{P}_{\mathrm{O}_{2}}^{1 / 2}\right)$, either before or after $\mathrm{CH}_{3}$ desorption, while $\mathrm{CO}$ forms predominantly via $\mathrm{CH}_{3}{ }^{*}$ reactions with gas-phase $\mathrm{O}_{2}$ $\left(\sim P_{\mathrm{O}_{2}}\right)$. These findings are consistent with the sequence

$$
\begin{gathered}
2 \mathrm{CH}_{3} \cdot \mathrm{M} \stackrel{k_{\mathrm{C}_{2}}}{\longrightarrow} \mathrm{C}_{2} \mathrm{H}_{6}+\mathrm{M} \\
\mathrm{CH}_{3} \cdot+\mathrm{O}_{2} \stackrel{k_{\mathrm{CO}}}{\longrightarrow} \mathrm{CO} \\
\mathrm{CH}_{3} \cdot \mathrm{O}^{*} \stackrel{{ }^{{ }_{\mathrm{CO}_{2}}}}{\longrightarrow} \mathrm{CO}_{2}
\end{gathered}
$$

in which M denotes a "third-body" that dissipates the energy released by radical recombination. These elementary steps and the assumptions of pseudosteady-state $\mathrm{CH}_{3}$ concentrations, quasi-equilibrated $\mathrm{O}_{2}$ dissociation, and low $\mathrm{O}_{\mathrm{s}}$ * coverages lead to rate equations of the form

$$
\begin{gathered}
r_{\mathrm{C}_{2}}=k_{\mathrm{C}_{2}} P_{\mathrm{CH}_{3}}^{2} \\
r_{\mathrm{CO}}=k_{\mathrm{CO}} P_{\mathrm{CH}_{3}} P_{\mathrm{O}_{2}} \\
P_{\mathrm{CH}_{3}}=\frac{\sqrt{B^{2}+4 k_{\mathrm{CO}_{2}} k^{\prime} P_{\mathrm{CH}_{4}} P_{\mathrm{CH}_{2}}^{1 / 2}}-B}{2 k_{\mathrm{C}_{2}} P_{\mathrm{O}_{2}}^{1 / 2}} \\
\left(\text { where } B=k_{\mathrm{CO}} P_{\mathrm{O}_{2}}+k_{\mathrm{CO}_{2}} P_{\mathrm{O}_{2}}^{1 / 2}\right)
\end{gathered}
$$

Regressed rate constants ${ }^{34}$ were obtained from rates measured as a function of $\mathrm{CH}_{4}$ and $\mathrm{O}_{2}$ pressures (data from Figure 2, panels $a$ and $b$ ). The curves drawn in Figure $7 a-c$ illustrate the accuracy of these kinetic descriptions of OCM pathways. The effects of $\mathrm{CH}_{4}$ and $\mathrm{O}_{2}$ pressures on $\mathrm{C}_{2}$ selectivities are given by eq 14 , which is derived from eqs 5 and $10-13$, together with the regressed values of their respective rate constants

$$
\frac{r_{\mathrm{C} 2}}{r_{\mathrm{CO}}+r_{\mathrm{CO}_{2}}}=\frac{1}{2}\left(\sqrt{1+\frac{4 k^{\prime} k_{\mathrm{C}_{2}} P_{\mathrm{CH}_{4}}}{\left(k_{\mathrm{CO}} P_{\mathrm{O}_{2}}^{1 / 2}+k_{\mathrm{CO}_{2}}\right)^{2} P_{\mathrm{O}_{2}}^{1 / 2}}}-1\right)
$$

At high selectivity ratios $(\sim>4)$, eq 14 can be simplified to

$$
\frac{r_{\mathrm{C} 2}}{r_{\mathrm{CO}}+r_{\mathrm{CO}_{2}}}=\sqrt{\frac{k^{\prime} k_{\mathrm{C}_{2}} P_{\mathrm{CH}_{4}}}{\left(k_{\mathrm{CO}} P_{\mathrm{O}_{2}}^{1 / 2}+k_{\mathrm{CO}_{2}}\right)^{2} P_{\mathrm{O}_{2}}^{1 / 2}}}
$$

because the $\left(4 k^{\prime} k_{\mathrm{C}_{2}} P_{\mathrm{CH}_{4}}\right) /\left[\left(k_{\mathrm{CO}} P_{\mathrm{O}_{2}}^{1 / 2}+k_{\mathrm{CO}_{2}}\right)^{2} P_{\mathrm{O}_{2}}^{1 / 2}\right]$ term is much larger than unity. This ratio increases with increasing $\mathrm{CH}_{4}$ pressure and decreasing $\mathrm{O}_{2}$ pressure (and thus with increasing $\mathrm{CH}_{4} / \mathrm{O}_{2}$ ratio) and also as surfaces become more reactive for $\mathrm{CH}_{4}$ activation to form $\mathrm{CH}_{3}$ radicals (larger $k^{\prime}$ ). The $k_{\mathrm{C}-\mathrm{H}}^{\prime} / k_{\mathrm{C}-\mathrm{D}}^{\prime}$ ratio obtained for $\mathrm{CH}_{4}$ and $\mathrm{CD}_{4}$ reactants (1.25; Table 1) and its use in eq 15 indicates that $\mathrm{C}_{2}$ selectivities at a give methane to oxygen reactant ratio $\left(\sim\left\{\left(k^{\prime} k_{\mathrm{C}_{2}}\right) /\left(k_{\mathrm{CO}} P_{\mathrm{O}_{2}}^{1 / 2}+k_{\mathrm{CO}_{2}}\right)^{2}\right\}^{1 / 2}\right)$ would be $\sim 2 \%$ lower for $\mathrm{CD}_{4}-\mathrm{O}_{2}$ than for $\mathrm{CH}_{4}-\mathrm{O}_{2}$ reactions. Measured selectivities are almost identical for $\mathrm{CH}_{4}$ and $\mathrm{CD}_{4}$ at each $\mathrm{O}_{2}$ pressure $(\sim 94 \%, \sim 82 \%$, and $\sim 78 \%$ selectivities at 0.9 , 1.8 , and $3.5 \mathrm{kPa} \mathrm{O}_{2}$, respectively). These similar selectivities may arise from positive but small isotope effects for $k_{\mathrm{CO}}$ and $k_{\mathrm{CO}_{2}}$, which reflect $\mathrm{H}$-abstraction from methyl radicals and which cancel those for the numerator $\left(k^{\prime} k_{\mathrm{C}_{2}}\right)$ in eq 15 . We note that the form of eq 15 accurately describes primary selectivities in anhydrous mixtures and that these selectivities depend predominantly on $\mathrm{CH}_{4} / \mathrm{O}_{2}$ reactant ratios.

3.4. $\mathrm{H}_{2} \mathrm{O}$-Mediated $\mathbf{C}-\mathrm{H}$ Bond Activation Pathways. We examine next the mechanistic basis for the strong effects of $\mathrm{H}_{2} \mathrm{O}$ on $\mathrm{CH}_{4}$ conversion rates and $\mathrm{C}_{2}$ selectivities and yields (Figures $1 \mathrm{a}$ and $\mathrm{1b}$ ). The activation of $\mathrm{C}-\mathrm{H}$ bonds in hydrocarbons by $\mathrm{H}_{2} \mathrm{O}$ without $\mathrm{O}_{2}$ co-reactants was probed using $\mathrm{CH}_{4} / \mathrm{H}_{2} \mathrm{O} / \mathrm{C}_{2} \mathrm{H}_{6}$ (or $\mathrm{C}_{2} \mathrm{H}_{4}$ ) reactants at $1073 \mathrm{~K}$ in a recirculating batch reactor. $\mathrm{CO}$ and $\mathrm{CO}_{2}$ were not detected at any conditions, indicating that steam reforming reactions of $\mathrm{CH}_{4}, \mathrm{C}_{2} \mathrm{H}_{6}$, or $\mathrm{C}_{2} \mathrm{H}_{4}$ did not occur. These data also show that any prevalent $\mathrm{H}_{2} \mathrm{O}$-mediated pathways require $\mathrm{O}_{2}$-derived $\mathrm{O} *$ species on catalytic surfaces for $\mathrm{OH}$ formation.

Laser-induced fluorescence was previously used to detect $\mathrm{OH}$ radicals when $\mathrm{H}_{2} \mathrm{O} / \mathrm{O}_{2}$ mixtures were exposed to solid basic oxides that also catalyze OCM reactions. ${ }^{19-21}$ The presence of $\mathrm{CH}_{4}$ decreased $\mathrm{OH}$ concentrations present in $\mathrm{H}_{2} \mathrm{O} / \mathrm{O}_{2}$ mixtures, suggesting that $\mathrm{CH}_{4}$ and $\mathrm{H}_{2} \mathrm{O}$ scavenge similar active oxygens at surfaces $\left(\mathrm{O}_{\mathrm{s}} *\right){ }^{21}$ Thus, we conclude that $\mathrm{OH}$ radicals form via the coupling of step 3 with

$$
\mathrm{H}_{2} \mathrm{O}+\mathrm{O}_{\mathrm{s}}^{*} \rightleftarrows \mathrm{OH}^{\bullet}+\mathrm{OH}^{*}
$$

in which $\mathrm{OH}^{*}$ and $\mathrm{OH}^{*}$ denote radical and chemisorbed species, respectively. Previous studies ${ }^{20}$ have shown that $\mathrm{OH}$ radicals reach equilibrium concentrations on $\mathrm{La}_{2} \mathrm{O}_{3}$ solids $\left(100 \mathrm{~Pa} \mathrm{H}_{2} \mathrm{O}\right.$ and $\mathrm{O}_{2} ; 1173 \mathrm{~K}$ ) via

$$
\mathrm{O}_{2}+2 \mathrm{H}_{2} \mathrm{O} \stackrel{K_{\mathrm{OH}^{\bullet}}}{\rightleftarrows} 4 \mathrm{OH}^{\bullet}
$$

as a consequence of equilibrated steps 1,3 , and 16 . OH radicals thus formed can subsequently abstract $\mathrm{H}$ atoms from $\mathrm{CH}_{4}$ via homogeneous pathways 


$$
\mathrm{CH}_{4}+\mathrm{OH}^{\bullet} \stackrel{k_{\mathrm{CH}_{4}-\mathrm{OH}^{\bullet}}^{\prime \prime}}{\longrightarrow} \mathrm{CH}_{3} \cdot+\mathrm{H}_{2} \mathrm{O}
$$

This reaction is exothermic by $59 \mathrm{~kJ} \mathrm{~mol}^{-1}$ at $1073 \mathrm{~K} .{ }^{35}$ When $\mathrm{OH}$ radicals are at equilibrium (via step 17), the rate of $\mathrm{C}-\mathrm{H}$ activation (via step 18) becomes proportional to $P_{\mathrm{O}_{2}}^{1 / 4} P_{\mathrm{H}_{2} \mathrm{O}}^{1 / 2}$. The combined rates of $\mathrm{CH}_{4}$ reactions via surface $\mathrm{O}_{\mathrm{s}} *$-mediated and $\mathrm{OH}-$ mediated $\mathrm{H}$-abstractions are then given by
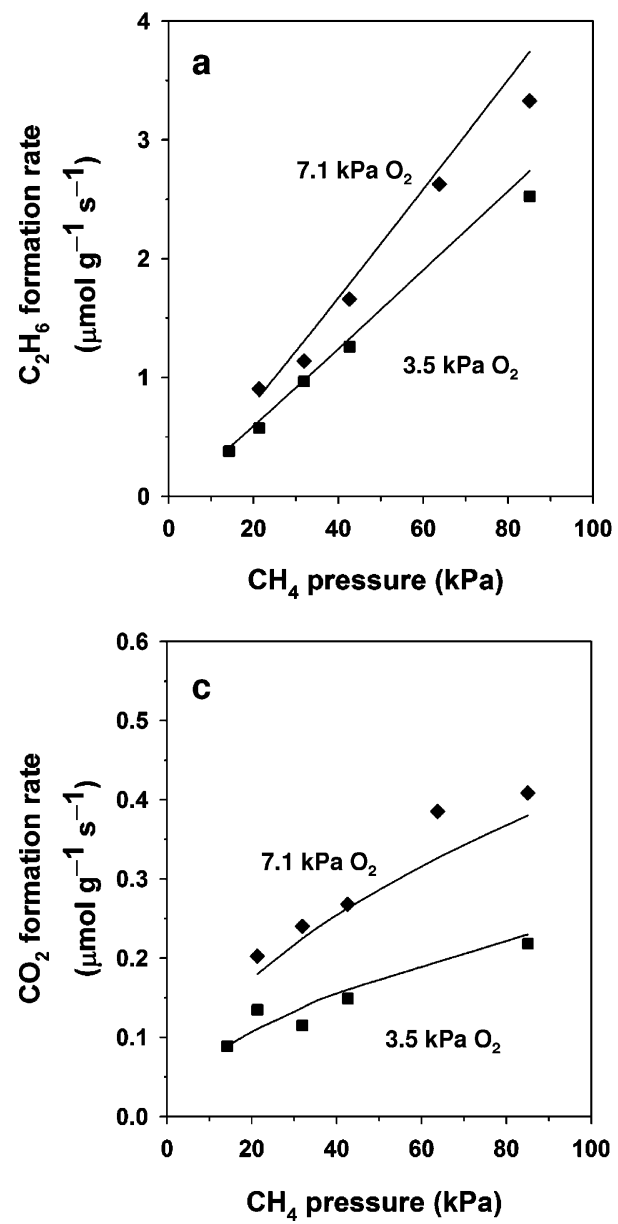

$$
r_{\mathrm{CH}_{4}}=k^{\prime} P_{\mathrm{CH}_{4}} P_{\mathrm{O}_{2}}^{1 / 2}+k^{\prime \prime} P_{\mathrm{CH}_{4}} P_{\mathrm{O}_{2}}^{1 / 4} P_{\mathrm{H}_{2} \mathrm{O}}^{1 / 2}
$$

where $k^{\prime \prime}$ is given by $k_{\mathrm{CH}_{4}}^{\prime \prime}-\mathrm{OH}^{\cdot} K_{\mathrm{OH}}^{1 / 4}, k_{\mathrm{CH}_{4}}^{\prime \prime}-\mathrm{OH}^{\cdot}$ is the rate constant for step 18, and $P_{\mathrm{O}_{2}}$ is the equilibrium constant for step 17. $\mathrm{H}_{2} \mathrm{O}$ pressures were determined at each point by an oxygen balance on reactants and products. Figure 8a shows that incremental $\mathrm{CH}_{4}$ conversion rates introduced by $\mathrm{H}_{2} \mathrm{O}$-mediated pathways (the difference between rates with and without $\mathrm{H}_{2} \mathrm{O}$

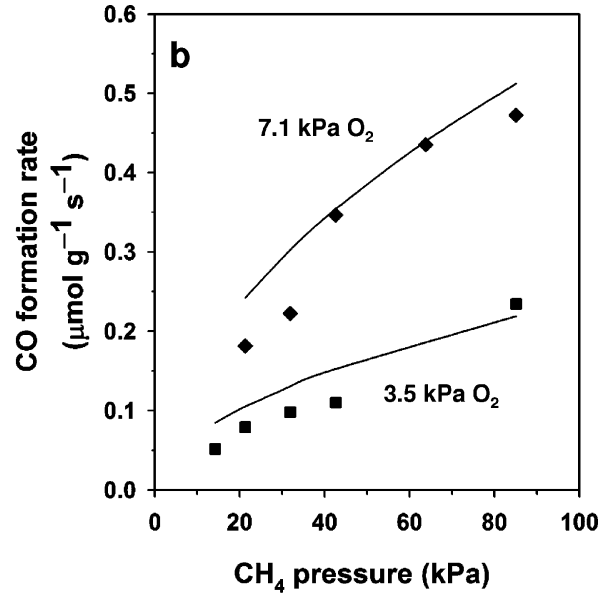

Figure 7. $\mathrm{C}_{2} \mathrm{H}_{6}(\mathrm{a}), \mathrm{CO}(\mathrm{b})$, and $\mathrm{CO}_{2}$ (c) formation rates extrapolated to zero conversion as a function of $\mathrm{CH}_{4}$ pressure measured in a flow reactor $(0.05 \mathrm{~g}, 1073 \mathrm{~K}, 101 \mathrm{kPa}$ total pressure, balance He). The curves denote the fitting results using optimized rate constants (eqs 10-13).
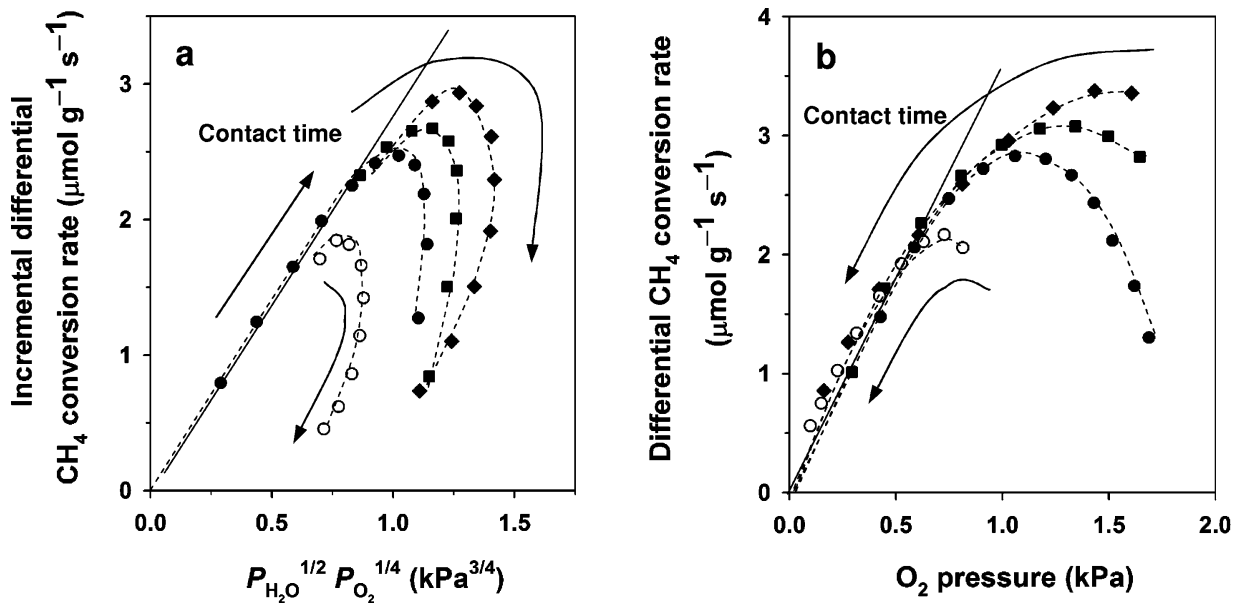

Figure 8. Incremental differential $\mathrm{CH}_{4}$ conversion rate (from measured differences between rates with and without $\mathrm{H}_{2} \mathrm{O}$ ) as a function of $P_{\mathrm{O}_{2}}^{1 / 4} P_{\mathrm{H}_{2} \mathrm{O}}^{1 / 2}$ (a) and (total) $\mathrm{CH}_{4}$ conversion differential rate as a function of $\mathrm{O}_{2}$ pressure (b) measured in a recirculating batch reactor. The arrows are in the direction of increasing contact time $\left(0.02 \mathrm{~g}, 1073 \mathrm{~K}\right.$, volume: $275-650 \mathrm{~cm}^{3}, 10.7 \mathrm{kPa} \mathrm{CH}_{4}, 101 \mathrm{kPa}$ total pressure, balance $\mathrm{He}$, $(\bullet) 1.8 \mathrm{kPa} \mathrm{O}_{2}$;

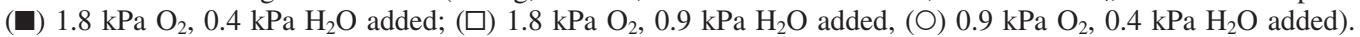


and given by the second term in eq 19) are proportional to $P_{\mathrm{O}_{2}}^{1 / 4} P_{\mathrm{H}_{2} \mathrm{O}}^{1 / 2}$ at low conversions (short contact times), consistent with quasi-equilibrated $\mathrm{OH}^{\bullet}$ formation steps (step 17) and with the kinetic relevance of $\mathrm{OH}$-mediated $\mathrm{H}$ abstraction (step 18). The rate constants for $\mathrm{OH}$-mediated $\mathrm{H}$ abstraction $\left(k^{\prime \prime} ; 0.21 \mu \mathrm{mol}\right.$ $\left.\mathrm{g}^{-1} \mathrm{~s}^{-1} \mathrm{kPa}^{-7 / 4}\right)$ and surface-mediated $\mathrm{H}$ abstraction $\left(k^{\prime} ; 0.04\right.$ $\mu \mathrm{mol} \mathrm{g}{ }^{-1} \mathrm{~s}^{-1} \mathrm{kPa}^{-3 / 2}$ ) at $1073 \mathrm{~K}$ give corresponding rates of 1.7 and $0.7 \mu \mathrm{mol} \mathrm{g}^{-1} \mathrm{~s}^{-1}$ for the two terms in eq 15 at $0.4 \mathrm{kPa}$ $\mathrm{H}_{2} \mathrm{O}\left(10.7 \mathrm{kPa} \mathrm{CH} \mathrm{CH}_{4} ; 1.8 \mathrm{kPa} \mathrm{O}_{2}\right.$ ), indicating the significant contributions from $\mathrm{OH}-$ mediated pathways at typical OCM conditions.

Figure $8 \mathrm{a}$ shows that differential $\mathrm{CH}_{4}$ conversion rates decrease abruptly at longer contact times, as $\mathrm{O}_{2}$ is essentially depleted from the reactant stream. These trends reflect a decrease in the rate of $\mathrm{O}_{2}$ chemisorption and an increase in the rate of scavenging of chemisorbed oxygen by $\mathrm{H}_{2} \mathrm{O}$ as $\mathrm{H}_{2} \mathrm{O}$ concentration increases with increasing conversion, which prevents step 1 and subsequent $\mathrm{O}_{\mathrm{s}}{ }^{*}$ reactions (step 16) from reaching equilibrium, because of their kinetic coupling with the $\mathrm{CH}_{4}$ and $\mathrm{H}_{2} \mathrm{O}$ activation steps that remove $\mathrm{O}_{\mathrm{s}}{ }^{*}$ (steps 2 and 16 , respectively). We note that $\mathrm{O}_{2}$ chemisorption (eq 1) and the $\mathrm{O}_{\mathrm{s}} *$ species formed are required for the ultimate activation of $\mathrm{CH}_{4}$ (step 2), $\mathrm{C}_{2}$ products, and $\mathrm{H}_{2} \mathrm{O}$ (step 16), irrespective of whether $\mathrm{C}-\mathrm{H}$ bond activation occurs directly by $\mathrm{O}_{\mathrm{s}} *$ species or by the $\mathrm{OH}$ radicals derived from such species. Figure $8 \mathrm{~b}$ shows that differential $\mathrm{CH}_{4}$ conversion rates become proportional to $\mathrm{O}_{2}$ pressure at low $\mathrm{O}_{2}$ concentrations $(<0.6 \mathrm{kPa})$ and modest $\mathrm{H}_{2} \mathrm{O}$ pressures $(>0.5 \mathrm{kPa})$, suggesting that $\mathrm{O}_{2}$ chemisorption steps indeed become kinetically relevant and nearly irreversible (step 20, forward reaction of step 1)

$$
\begin{gathered}
\mathrm{O}_{2}+2 * \stackrel{k_{\mathrm{O}_{2}}}{\longrightarrow} 2 \mathrm{O}_{\mathrm{s}} * \\
r=k_{\mathrm{O}_{2}} P_{\mathrm{O}_{2}}
\end{gathered}
$$

where $K_{\mathrm{O}_{2}}$ is approximately $3.6 \mu \mathrm{mol} \mathrm{g}-1 \mathrm{~s}^{-1} \mathrm{kPa}^{-1}$. The rate constant calculated from the collision frequency of $\mathrm{O}_{2}$ with surfaces at $1073 \mathrm{~K}$ is $3 \times 10^{7} \mu \mathrm{mol} \mathrm{g}-1 \mathrm{~s}^{-1} \mathrm{kPa}^{-1}$, indicating that sticking coefficients are $\sim 10^{-7}$, a small value consistent with the low concentration of $\mathrm{O}_{\mathrm{s}}^{*}$ prevalent during steady-state OCM reactions. We note that, when $\mathrm{H}_{2} \mathrm{O}$ is present at significant concentrations, its activation (step 16) is considered to remain much faster in both forward and reverse directions than $\mathrm{H}$-abstraction from $\mathrm{CH}_{4}$ on the catalyst surface (step 2) at OCM practical conditions where $\mathrm{H}_{2} \mathrm{O}$ prevails: therefore, even at low $\mathrm{O}_{2}$ concentrations, the presence of $\mathrm{H}_{2} \mathrm{O}$ (e.g., at high $\mathrm{CH}_{4}$ conversions) leads to predominant activation of $\mathrm{CH}_{4}$ via $\mathrm{OH}-$ mediated instead of surface $\left(\mathrm{O}_{\mathrm{s}}{ }^{*}\right)$-mediated routes.

When prevalent $\mathrm{O}_{2}$ pressures ensure quasi-equilibrated $\mathrm{OH}^{\bullet}$ concentrations, $\mathrm{CH}_{4} / \mathrm{O}_{2} / \mathrm{H}_{2} \mathrm{O}$ and $\mathrm{CH}_{4} / \mathrm{O}_{2} / \mathrm{D}_{2} \mathrm{O}$ mixtures should react at similar rates because of the weak nature of the consequent thermodynamic H/D isotope effects on $\mathrm{OH} / \mathrm{OD}$ concentrations. The data in Table 1 show that the measured $\mathrm{KIE}$ for $\mathrm{CH}_{4} / \mathrm{O}_{2} / \mathrm{D}_{2} \mathrm{O}$ mixtures, given by

$$
\mathrm{KIE}=\left(\frac{k_{\mathrm{CH}_{4}-\mathrm{OH}^{\circ}}^{\prime \prime}}{k_{\mathrm{CH}_{4}-\mathrm{OD}^{\circ}}^{\prime \prime}}\right)\left(\frac{K_{\mathrm{OH}}}{K_{-\mathrm{OD}^{\circ}}}\right)^{1 / 4}
$$

is 1.08. In eq $22, K_{\mathrm{OD}}$. and $k_{\mathrm{CH}_{4}}^{\prime \prime}$ - OD. are the equilibrium and rate constants for steps 23 and 24 , respectively.

$$
\begin{gathered}
\mathrm{O}_{2}+2 \mathrm{D}_{2} \mathrm{O} \stackrel{K_{\mathrm{OD}}}{\rightleftarrows} 4 \mathrm{OD}^{\bullet} \\
\mathrm{CH}_{4}+\mathrm{OD}^{\bullet} \stackrel{k_{\mathrm{CH}_{4}-\mathrm{OD}^{\bullet}}^{\prime \prime}}{\longrightarrow} \mathrm{CH}_{3} \cdot \mathrm{HDO}
\end{gathered}
$$

Using available thermodynamic data for entropy and enthalpy and their temperature dependence, ${ }^{35}\left(K_{\mathrm{OH}^{*}} / K_{\mathrm{OD}}\right)^{1 / 4}$ was estimated to be 1.04 at $1073 \mathrm{~K}$. Experimental data for the rate constant of step 24 are unavailable at relevant temperatures $(\sim 1000 \mathrm{~K})$, but the $\left(k_{\mathrm{CH}_{4}-\mathrm{OH} \cdot}^{\prime \prime} / k_{\mathrm{CH}_{4}-\mathrm{OD}}^{\prime \prime}\right)$ ratio is expected to be near unity at $1073 \mathrm{~K}$ because both numerator and denominator terms involve the activation of a $\mathrm{C}-\mathrm{H}$ bond and the formation of a $\mathrm{O}-\mathrm{H}$ bond. ${ }^{36,37}$ Thus, the overall KIE value (eq 22) is expected to be very close to unity, consistent with measured values (1.08, Table $1)$.

$\mathrm{OH}$-mediated pathways for activation of $\mathrm{C}-\mathrm{H}$ bonds in $\mathrm{CH}_{4}$ in kinetically-relevant steps (step 18) would give normal KIE values for $\mathrm{CD}_{4}-\mathrm{O}_{2}-\mathrm{H}_{2} \mathrm{O}$ reactants. Table 1 shows that the measured KIE value was 1.44 for these reactants, consistent with kinetically-relevant $\mathrm{C}-\mathrm{H}$ bond cleavage in $\mathrm{CH}_{4}$ (step 18). The absence of $\mathrm{CH}_{x} \mathrm{D}_{4-x}(0<x<4)$ isotopomers during reactions of $\mathrm{CH}_{4} / \mathrm{D}_{2} \mathrm{O} / \mathrm{O}_{2}$ or $\mathrm{CD}_{4} / \mathrm{H}_{2} \mathrm{O} / \mathrm{O}_{2}$ mixtures confirms the irreversible nature of $\mathrm{CH}_{4}$ activation steps (steps 2 and 18) and avoids the isotopic dilution of methane that would otherwise prevail. These measured KIE values reflect the combined contributions of surface-catalyzed and $\mathrm{OH}$-mediated $\mathrm{C}-\mathrm{H}$ bond activation. The rates and corresponding $\mathrm{KIE}$ for $\mathrm{OH}$-mediated pathways (the second term in eq 19) can be obtained by subtracting the rates for anhydrous pathways (the first term in eq 19) obtained in section 3.2 from the measured rates for each methane isotopomer. The KIE value for $\mathrm{OH}$-mediated pathways, given by

$$
\begin{gathered}
\mathrm{KIE}=\frac{k_{\mathrm{CH}_{4}-\mathrm{OH}^{\bullet}}^{\prime \prime}}{k_{\mathrm{CD}_{4}-\mathrm{OH}^{\bullet}}^{\prime \prime}} \\
\mathrm{CD}_{4}+\mathrm{OH}^{\bullet} \stackrel{{ }_{\mathrm{CD}_{4}-\mathrm{OH}^{\bullet}}^{\prime \prime}}{\longrightarrow} \mathrm{CD}_{3}^{\bullet}+\mathrm{HDO}
\end{gathered}
$$

where $k_{\mathrm{CH}_{4}-\mathrm{OH}}^{\prime \prime}$ and $k_{\mathrm{CD}_{4}-\mathrm{OH}^{*}}^{\prime \prime}$ are rate constants for steps 18 and 26 , respectively, is 1.58 . We note that this small KIE value for $\mathrm{H}$-abstraction by $\mathrm{OH}^{*}$ is consistent with high reactivity of $\mathrm{OH}^{*}$ leading to relatively product character and to a relatively late transition state, in which $\mathrm{C}-\mathrm{H}$ bonds would be essentially cleaved. The involvement of less reactive radicals, such as $\mathrm{H}$, $\mathrm{O}$, and $\mathrm{HO}_{2}$ in $\mathrm{C}-\mathrm{H}$ bond activation, as discussed in the next section, would lead to KIE values larger than for abstraction of $\mathrm{H}$ atoms exclusively by $\mathrm{OH}$.

We examine next the temperature dependence of $\mathrm{OH}-$ mediated pathways (the second term in eq 19) by measuring $k^{\prime}$ at $993-1123 \mathrm{~K}$ and $\mathrm{O}_{2}$ pressures sufficient for quasi-equilibrated $\mathrm{O}_{2}$ chemisorption (>1.5 $\mathrm{kPa}$ ) (Figure 3 ). This activation energy $\left(E_{\text {app }}^{\prime \prime} ; 161 \pm 9 \mathrm{~kJ} \mathrm{~mol}^{-1}\right.$ ) reflects the combined contributions from the activation barrier for $\mathrm{H}$-abstraction from $\mathrm{CH}_{4}$ by $\mathrm{OH}^{\bullet}$ $\left(E_{\mathrm{a}, \mathrm{OH}}\right)$ (eq 18), and the enthalpy for quasi-equilibrated $\mathrm{OH}$ radical formation reactions $\left(\Delta H_{\mathrm{OH}}\right.$, step 17$)$

$$
\mathrm{E}_{\mathrm{a}, \mathrm{app}}^{\prime \prime}=\mathrm{E}_{\mathrm{a}, \mathrm{OH}}+\frac{1}{4} \Delta \mathrm{H}_{\mathrm{OH}}
$$

The reported value of $\Delta H_{\mathrm{OH}}$ (for step 17) at $1073 \mathrm{~K}$ is 650 $\mathrm{kJ} \mathrm{mol}^{-1,35}$ thus, eq 27 gives a $E_{\mathrm{a}, \mathrm{OH}}$ value for $\mathrm{C}-\mathrm{H}$ bond activation by $\mathrm{OH}$ radicals of nearly zero $\left(0 \pm 9 \mathrm{~kJ} \mathrm{~mol}^{-1}\right)$. Such 


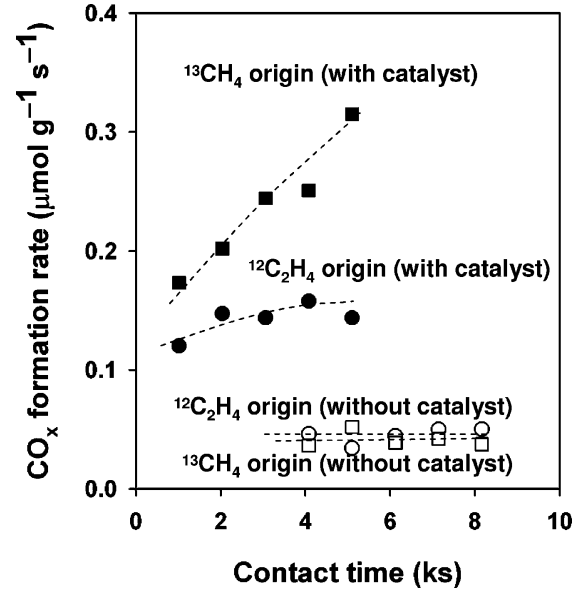

Figure 9. $\mathrm{CH}_{4}$ conversion and $\mathrm{C}_{2} \mathrm{H}_{4}$ conversion to $\mathrm{CO}_{x}$ in the presence and the absence of the catalyst, as a function of contact time for ${ }^{13} \mathrm{CH}_{4} /$ ${ }^{12} \mathrm{C}_{2} \mathrm{H}_{4} / \mathrm{O}_{2}$ reaction. Line denotes regressed rates $(0.02 \mathrm{~g}, 1073 \mathrm{~K}$, volume: $475 \mathrm{~cm}^{3}, 10.7 \mathrm{kPa}{ }^{13} \mathrm{CH}_{4}, \mathrm{CH}_{4} / \mathrm{O}_{2}=6,0.4 \mathrm{kPa}{ }^{12} \mathrm{C}_{2} \mathrm{H}_{4}$, total pressure $101 \mathrm{kPa}$, balance $\mathrm{He},\left(\bullet{ }^{12} \mathrm{C}_{2} \mathrm{H}_{4}\right.$ conversion to $\mathrm{CO}_{x}$ in the presence of catalyst; $(\mathrm{O}){ }^{12} \mathrm{C}_{2} \mathrm{H}_{4}$ conversion to $\mathrm{CO}_{x}$ in the absence of catalyst; ( $\square){ }^{13} \mathrm{CH}_{4}$ conversion to $\mathrm{CO}_{x}$ in the presence of catalyst; ( $\square$ ) ${ }^{13} \mathrm{CH}_{4}$ conversion to $\mathrm{CO}_{x}$ in the absence of catalyst).

small activation barriers $\left(27 \mathrm{~kJ} \mathrm{~mol}^{-1}\right)^{38}$ have been previously reported for this reaction (step 18). These activation energies are much smaller than those for surface-mediated $\mathrm{C}-\mathrm{H}$ bond activation pathways $\left(290 \mathrm{~kJ} \mathrm{~mol}^{-1}\right)$, confirming the very reactive nature of $\mathrm{OH}$ radicals compared with chemisorbed oxygen $\left(\mathrm{O}_{\mathrm{s}}{ }^{*}\right)$ species and the proposed late nature of transition states for $\mathrm{OH}-$ mediated $\mathrm{C}-\mathrm{H}$ bond activation pathways.

3.5. Effects of $\mathrm{H}_{2} \mathrm{O}$ on Primary and Secondary Reactions in Oxidative Coupling of Methane. 3.5.1. Isotopic Tracer Studies for OCM Reaction Pathways. Accurate measurements of kinetic constants in sequential reaction pathways (scheme 1) require the use of isotopic tracers, in which ${ }^{13} \mathrm{CH}_{4} / \mathrm{O}_{2}$ reactants are used together with unlabeled versions of the various ${ }^{12} \mathrm{C}_{2}+$ products with and without the presence of $\mathrm{H}_{2} \mathrm{O}$. First, we examine the extent to which purely homogeneous pathways contribute to reactions of $\mathrm{CH}_{4}$ and $\mathrm{OCM}$ products at $1073 \mathrm{~K}$ within an empty reactor.

Figure 9 shows rates of ${ }^{13} \mathrm{CH}_{4}$ and ${ }^{12} \mathrm{C}_{2} \mathrm{H}_{4}$ conversion rates to $\mathrm{CO}_{\mathrm{x}}$ during reactions of ${ }^{13} \mathrm{CH}_{4} /{ }^{12} \mathrm{C}_{2} \mathrm{H}_{4} / \mathrm{O}_{2}$ mixtures as a function of contact time in an empty reactor and compares these data with those measured in this reactor with $\mathrm{Mn} / \mathrm{Na}_{2} \mathrm{WO}_{4} / \mathrm{SiO}_{2}$ $(0.02 \mathrm{~g}) .{ }^{13} \mathrm{CH}_{4}$ and ${ }^{12} \mathrm{C}_{2} \mathrm{H}_{4}$ conversion rates to $\mathrm{CO}_{\mathrm{x}}$ were smaller by factors of $\sim 10$ and $\sim 4$, respectively, when the catalyst was absent. Similar experiments with ${ }^{13} \mathrm{CH}_{4} /{ }^{12} \mathrm{C}_{2} \mathrm{H}_{6} / \mathrm{O}_{2}$ reactants showed that ${ }^{12} \mathrm{C}_{2} \mathrm{H}_{6}$ conversion rates were also $\sim 10$ times smaller for purely homogeneous pathways. These data show that kinetically-relevant $\mathrm{C}-\mathrm{H}$ bond activation in $\mathrm{CH}_{4}, \mathrm{C}_{2} \mathrm{H}_{6}$, and $\mathrm{C}_{2} \mathrm{H}_{4}$ molecules occurs predominantly via catalytic routes (both surface-mediated and homogeneous $\mathrm{OH}$-mediated pathways, in which $\mathrm{OH}$ radicals form on surfaces).

Reactions of ${ }^{13} \mathrm{CH}_{4} /{ }^{12} \mathrm{C}_{2} \mathrm{H}_{6} / \mathrm{O}_{2}$ and ${ }^{13} \mathrm{CH}_{4} /{ }^{12} \mathrm{C}_{2} \mathrm{H}_{4} / \mathrm{O}_{2}$ mixtures in an empty reactor gave primary ${ }^{13} \mathrm{C}_{2} \mathrm{H}_{6}$ selectivities (from $\left.{ }^{13} \mathrm{CH}_{4}\right)$ much lower $(\sim 65 \%)$ than when a catalyst was present ( $\sim 80 \%$ ) (Figure S3; Supporting Information); these trends reflect the slower formation of $\mathrm{CH}_{3}$ radicals (from ${ }^{13} \mathrm{CH}_{4}$ ) when catalytic surfaces are not present. Homogeneous pathways also led to a stronger decrease in $\mathrm{C}_{2}$ selectivity with increasing contact time than catalytic pathways (Figure S3; Supporting Information), consistent with the prevalence of $\mathrm{C}-\mathrm{H}$ bond activation by less reactive $\mathrm{H}$-abstractors (such as $\mathrm{H}$ and $\mathrm{CH}_{3}$ ); these less reactive abstractors more strongly favor activation of
TABLE 2: First Order Rate Constants $\left(\mu \mathrm{mol} \mathrm{g} \mathbf{g}^{-1} \mathbf{s}^{-1} \mathbf{k P a}^{-1}\right)$ Measured by Isotopic Tracer Experiments in a Recirculating Reactor for Steps in Scheme 1, for Surface-Mediated $\left(\mathrm{O}_{\mathrm{s}}{ }^{*}\right)$ and $\mathrm{OH}^{\circ}$-Mediated Pathways $(0.02$ g, $1073 \mathrm{~K}$, Unit Volume: 475-550 $\mathrm{cm}^{3}, 10.7 \mathrm{kPa} \mathrm{CH}, \mathrm{CH}_{4} / \mathrm{O}_{2}=6,101 \mathrm{kPa}$ Total Pressure, Balance He)

\begin{tabular}{lcccccccl}
\hline & $k_{1}^{\prime}$ & $k_{2}^{\prime}$ & $k_{3}^{\prime a}$ & $k_{4}^{\prime a}$ & $k_{5}^{\prime b}$ & $k_{6}^{\prime b}$ & $k_{7}^{\prime c}$ & $k_{8}^{\prime d}$ \\
\hline surface-mediated $^{\prime}$ & 0.05 & 0.01 & 1.7 & 0.14 & 0.12 & 0.22 & 0.59 & 0.42 \\
OH-mediated $^{e}$ & 0.16 & 0.02 & 1.1 & 0.12 & 0.03 & 0.10 & 0.36 & 0
\end{tabular}

${ }^{a} 0.4 \mathrm{kPa}{ }^{12} \mathrm{C}_{2} \mathrm{H}_{6}$ added to ${ }^{13} \mathrm{CH}_{4}-\mathrm{O}_{2}$ mixture. ${ }^{b} 0.4 \mathrm{kPa}{ }^{12} \mathrm{C}_{2} \mathrm{H}_{4}$ added to ${ }^{13} \mathrm{CH}_{4}-\mathrm{O}_{2}$ mixture. ${ }^{c} 0.2 \mathrm{kPa}{ }^{12} \mathrm{C}_{3} \mathrm{H}_{6}$ added to ${ }^{13} \mathrm{CH}_{4}-\mathrm{O}_{2}$ mixture. ${ }^{d} 0.2$ or $0.5 \mathrm{kPa}{ }^{13} \mathrm{CO}$ added to ${ }^{12} \mathrm{CH}_{4}-\mathrm{O}_{2}$ mixture. ${ }^{e} 0.4$ $\mathrm{kPa} \mathrm{H}_{2} \mathrm{O}$ added, from rate differences with and without $\mathrm{H}_{2} \mathrm{O}$.

molecules, such as $\mathrm{C}_{2} \mathrm{H}_{6}$, with weaker $\mathrm{C}-\mathrm{H}$ bonds than those in $\mathrm{CH}_{4}$ compared with more reactive abstractors. ${ }^{13} \mathrm{CH}_{4}$ conversion rates and ${ }^{13} \mathrm{C}_{2} \mathrm{H}_{6} /{ }^{13} \mathrm{CO}_{\mathrm{x}}$ product ratios were not affected by adding ${ }^{12} \mathrm{C}_{2} \mathrm{H}_{6}$ or ${ }^{12} \mathrm{C}_{2} \mathrm{H}_{4}$ to ${ }^{13} \mathrm{CH}_{4} / \mathrm{O}_{2}$ reactants in either empty reactors or in those containing catalysts. These data confirm our previous conclusions that $\mathrm{C}_{2}$ products cannot give rise to the changes in rates and selectivities observed as conversion increases with increasing contact time (Figure 1a).

First-order rate constants for all reactions in Scheme 1 were measured by isotopic tracing using ${ }^{13} \mathrm{CH}_{4} / \mathrm{O}_{2}$ reactants mixed with ${ }^{12} \mathrm{C}_{2} \mathrm{H}_{6},{ }^{12} \mathrm{C}_{2} \mathrm{H}_{4}$, or ${ }^{12} \mathrm{C}_{3} \mathrm{H}_{6}$ in the presence and absence of added $\mathrm{H}_{2} \mathrm{O}$ on $\mathrm{Mn} / \mathrm{Na}_{2} \mathrm{WO}_{4} / \mathrm{SiO}_{2}$ at $1073 \mathrm{~K}$. Measured rates were extrapolated to zero conversions so that they reflect the $\mathrm{H}_{2} \mathrm{O}$ pressure in the starting reactant mixture in both cases $(0$ or $0.4 \mathrm{kPa} \mathrm{H}_{2} \mathrm{O}$ ) before $\mathrm{H}_{2} \mathrm{O}$ forms via OCM reactions. Table 2 shows rate constants under anhydrous conditions ("surfacemediated" pathways) and via OH-mediated pathways, estimated by comparing data with and without added $\mathrm{H}_{2} \mathrm{O}$. The rate constants for steps $1-7$ in Scheme $1\left(k_{1}^{\prime}-k_{7}^{\prime}\right)$ are all nonzero for $\mathrm{OH}$-mediated pathways, indicating that $\mathrm{H}_{2} \mathrm{O}$ provides independent pathways for the activation of $\mathrm{C}-\mathrm{H}$ bonds in all hydrocarbons. Thus, the beneficial effects of $\mathrm{H}_{2} \mathrm{O}$ and the concomitant contributions of $\mathrm{OH}$-mediated pathways must reflect the different (and more desirable) preference with which these pathways activate $\mathrm{C}-\mathrm{H}$ bonds in $\mathrm{CH}_{4}, \mathrm{C}_{2} \mathrm{H}_{6}, \mathrm{C}_{2} \mathrm{H}_{4}$, and $\mathrm{C}_{3} \mathrm{H}_{6}$ relative to the corresponding steps mediated by $\mathrm{O}_{\mathrm{s}}{ }^{*}$ species at surfaces, which prevail under anhydrous conditions.

The $k_{1}^{\prime} / k_{2}^{\prime}$ ratios ( $k_{j}$ for steps in Scheme 1) were larger for $\mathrm{OH}$-mediated $(\sim 8)$ than for surface-mediated $(\sim 5)$ routes (Table 2), consistent with the higher initial $\mathrm{C}_{2}$ selectivities measured when $\mathrm{H}_{2} \mathrm{O}$ was present (Figure 1b). These data reflect an increase in $\mathrm{CH}_{3}$ formation rates as a result of additional $\mathrm{CH}_{4}$ activation pathways mediated by $\mathrm{OH}$ radicals and introduced by $\mathrm{H}_{2} \mathrm{O}$ molecules and their activation on catalyst surfaces (step 18). These higher radical concentrations increase the rate of bimolecular $\mathrm{CH}_{3}{ }^{\bullet}$ recombination steps (eq 10) relative to that for unimolecular $\mathrm{CH}_{3}{ }^{\circ}$ oxidation to $\mathrm{CO}_{\mathrm{x}}$ (eqs 11 and 12). $\mathrm{CH}_{3}$ radical formation via $\mathrm{OH}-$ mediated pathways $\left(r_{\mathrm{CH}_{4}}=k^{*} P_{\mathrm{CH}_{4}} P_{\mathrm{O}_{2}}^{1 / 4} P_{\mathrm{H}_{2} \mathrm{O}}^{1 / 2}\right)$ gives a selectivity ratio of the form

$$
\frac{r_{\mathrm{C} 2}}{r_{\mathrm{CO}}+r_{\mathrm{CO}_{2}}}=\frac{1}{2}\left(\sqrt{1+\frac{4 k_{\mathrm{C}_{2}} k^{\prime \prime} P_{\mathrm{CH}_{4}} P_{\mathrm{H}_{2} \mathrm{O}}^{1 / 2}}{\left(k_{\mathrm{CO}}+k_{\mathrm{CO}_{2}} \mathrm{P}_{\mathrm{O}_{2}}^{1 / 2}\right)^{2} P_{\mathrm{O}_{2}}^{3 / 4}}}-1\right)
$$

which simplifies to eq 29 at the high prevalent selectivity ratios $(>4)$ 


$$
\frac{r_{\mathrm{C} 2}}{r_{\mathrm{CO}}+r_{\mathrm{CO}_{2}}}=\sqrt{\frac{k_{\mathrm{C}_{2}} k^{\prime \prime} P_{\mathrm{CH}_{4}} P_{\mathrm{H}_{2} \mathrm{O}}^{1 / 2}}{\left(k_{\mathrm{CO}} P_{\mathrm{O}_{2}}^{1 / 2}+k_{\mathrm{CO}_{2}}\right)^{2} P_{\mathrm{O}_{2}}^{3 / 4}}}
$$

The ratio expected from rate constants measured under anhydrous conditions is $\sim 13$, while measured values are $\sim 8$, apparently because of small contributions from less reactive (and more sensitive to $\mathrm{C}-\mathrm{H}$ bond strengths) radicals (e.g., $\mathrm{H}, \mathrm{HO}_{2}$ ), which would give ratios higher than predicted from eq 29 , because of higher $k_{\mathrm{CO}}$ and $k_{\mathrm{CO}_{2}}$ values.

Next, we compare the relative rates of activation of $\mathrm{C}-\mathrm{H}$ bonds in $\mathrm{CH}_{4}, \mathrm{C}_{2} \mathrm{H}_{6}$, and $\mathrm{C}_{2} \mathrm{H}_{4}$ via $\mathrm{H}$-abstraction on surfaces $\left(\mathrm{O}_{\mathrm{s}}^{*}\right)$ and with $\mathrm{OH}$ radicals in the context of the rate constants reported in Table 2. The ubiquitous decrease in $\mathrm{C}_{2}+$ selectivities observed with increasing $\mathrm{CH}_{4}$ conversion and contact time reflects the relative reactivities of reactants and products, which arises, in turn, from their different rate constants. Figure 10 shows the ratios of $\mathrm{C}_{2} \mathrm{H}_{6}$ and $\mathrm{C}_{2} \mathrm{H}_{4}$ activation rate constants relative to those for $\mathrm{CH}_{4}$ activation via surface-catalyzed and $\mathrm{OH}$-mediated routes together with the homolytic dissociation energies for each of the $\mathrm{C}-\mathrm{H}$ bonds involved. These ratios are smaller for $\mathrm{OH}$-mediated than for surface-mediated pathways, consistent with the higher $\mathrm{C}_{2}$ yields attained when $\mathrm{H}_{2} \mathrm{O}$ was present (Figure 1b). These rate constant ratios decreased monotonically with increasing $\mathrm{C}-\mathrm{H}$ bond energies for $\mathrm{OH}-$ mediated pathways (Figure 10), consistent with the sole kineticrelevance and homolytic character of the $\mathrm{H}$-abstraction steps involved. Rate constant ratios agree well with those expected from ratios reported for the corresponding rate constants for $\mathrm{H}$-abstraction by $\mathrm{OH}$ radicals via homogeneous reactions at 1073 $\mathrm{K}\left(\mathrm{CH}_{4}, 1.6 \times 10^{12} ; \mathrm{C}_{2} \mathrm{H}_{6}, 5.5 \times 10^{12} ; \mathrm{C}_{2} \mathrm{H}_{4}, 1.2 \times 10^{12} \mathrm{~cm}^{3}\right.$ $\left.\mathrm{mol}^{-1} \mathrm{~s}^{-1}\right),{ }^{38}$ consistent with the involvement of these gas-phase radicals in the kinetically-relevant steps for the activation of $\mathrm{C}-\mathrm{H}$ bonds in $\mathrm{CH}_{4}$ and $\mathrm{C}_{2}$ hydrocarbons. The activation barriers for such steps follow Brønsted-Evans-Polanyi relations ${ }^{39}$

$$
\mid \Delta E_{\mathrm{a}} \mathrm{l}=\alpha \Delta \mathrm{|} \Delta H_{\mathrm{r}}^{\circ} \mathrm{|}
$$

where $\alpha$ is the Brønsted-Evans-Polanyi parameter, $\Delta E_{\mathrm{a}}$ is the difference between the activation energies for two homologous steps, and $\Delta \mid \Delta H_{\mathrm{r}} \mathrm{I}$ is the difference between the respective reaction enthalpies (in this case given by differences in $\mathrm{C}-\mathrm{H}$

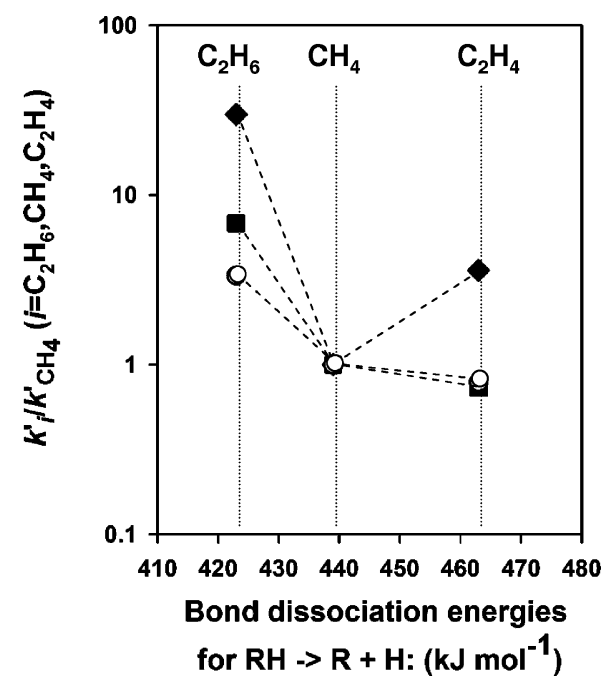

Figure 10. Ratio of rate constants for conversion of $\mathrm{C}_{2} \mathrm{H}_{6}\left(k_{3}^{\prime}+k_{4}^{\prime}\right)$ and $\mathrm{C}_{2} \mathrm{H}_{4}\left(k_{5}^{\prime}+k_{6}^{\prime}\right)$ to that for conversion of $\mathrm{CH}_{4}\left(k_{1}^{\prime}+k_{2}^{\prime}\right)$ as a function of $\mathrm{C}-\mathrm{H}$ bond dissociation energies. ( $)$ Surface-mediated pathway; (匹) $\mathrm{OH}$-mediated pathway; $(\mathrm{O}) \mathrm{H}$ abstraction by $\mathrm{OH}$ radicals in the gas-phase. $^{38}$ bond strengths). Similar monotonic trends were not evident for surface-mediated pathways (Figure 10), for which $\mathrm{C}_{2} \mathrm{H}_{4}$ molecules appear to react much faster than expected from the strength of their $\mathrm{C}-\mathrm{H}$ bonds, apparently because their $\pi$-electrons lead to stronger interactions with Lewis acid sites on oxide catalyst surfaces.

The combined rate constants for $\mathrm{C}_{2} \mathrm{H}_{6}$ activation $\left(k_{3}^{\prime}+k_{4}^{\prime}\right)$ were $\sim 30$ times larger than for $\mathrm{CH}_{4}$ activation $\left(k_{1}^{\prime}+k_{2}^{\prime}\right)$ in the case of the surface-mediated pathways prevalent under anhydrous conditions, as expected from the weaker $\mathrm{C}-\mathrm{H}$ bonds in $\mathrm{C}_{2} \mathrm{H}_{6}\left(423 \mathrm{~kJ} \mathrm{~mol}^{-1}\right)$ compared with those in $\mathrm{CH}_{4}(439 \mathrm{~kJ}$ $\left.\mathrm{mol}^{-1}\right){ }^{32}$ This ratio was much smaller (6.8) for $\mathrm{OH}$-mediated pathways, even though both surface-mediated and $\mathrm{OH}$-mediated routes involve kinetically-relevant $\mathrm{C}-\mathrm{H}$ bond activation in $\mathrm{CH}_{4}$ and $\mathrm{C}_{2} \mathrm{H}_{6}$. Thus, the different specificity for $\mathrm{C}-\mathrm{H}$ bond activation via these pathways must reflect differences in the reactivity of the two abstractors involved (i.e., $\mathrm{OH}^{*}$ and $\mathrm{O}_{\mathrm{s}}{ }^{*}$ ) and in their sensitivity to $\mathrm{C}-\mathrm{H}$ bond energies.

Abstractors that form stronger bonds with $\mathrm{H}$-atoms react with lower sensitivity to the strength of the $\mathrm{C}-\mathrm{H}$ bond being activated. We have previously shown that reactions with energetic $\mathrm{H}$-abstractors, such as $\mathrm{OH}$ radicals, react less selectively with the weaker $\mathrm{C}-\mathrm{H}$ bonds in $\mathrm{HCHO}$ (relative to stronger $\mathrm{C}-\mathrm{H}$ bonds in $\mathrm{CH}_{4}$ ) than more stable radicals, such as $\mathrm{O}$ and $\mathrm{HO}_{2} \cdot{ }^{40} \mathrm{OH}$ radicals are among the most thermodynamically unstable and reactive $\mathrm{H}$-abstractors; they form very strong $\mathrm{O}-\mathrm{H}$ bonds within the stable $\mathrm{H}_{2} \mathrm{O}$ molecules formed in such processes. ${ }^{18}$ The ratio of the rate constants for $\mathrm{H}$-abstraction from ethane and methane by gas-phase $\mathrm{OH}$ radicals $\left(k_{\mathrm{C}_{2} \mathrm{H}_{6}}^{\mathrm{OH}} / k_{\mathrm{CH}_{4}}^{\mathrm{OH}}\right)$ is 3.3-4.4. ${ }^{14,38} \mathrm{OH}$-mediated pathways in OCM reactions give values slightly higher than these (6.8; Table 2), but much smaller than for surface-mediated pathways (30). We surmise that measured $k_{\mathrm{C}_{2} \mathrm{H}_{6}}^{\mathrm{OH}} / k_{\mathrm{CH}_{4}}^{\mathrm{OH}}$ ratios are higher than reported for $\mathrm{H}$ abstraction by $\mathrm{OH}$ radicals, ${ }^{14,38}$ because of parallel contributions from $\mathrm{CH}_{3}{ }^{\circ}+\mathrm{C}_{2} \mathrm{H}_{6} \rightarrow \mathrm{CH}_{4}+\mathrm{C}_{2} \mathrm{H}_{5} \cdot$ reactions and perhaps also from reactions with $\mathrm{O}$ and $\mathrm{HO}_{2}$ radicals, which are less reactive than $\mathrm{OH}$ radicals. Contributions from these less reactive radicals to $\mathrm{C}-\mathrm{H}$ bond activation would lead to KIE values larger than from exclusive $\mathrm{OH}$-mediated $\mathrm{H}$-abstraction from $\mathrm{CH}_{4}$ (Table $1)$, as mentioned in section 3.4 .

$\mathrm{C}_{2} \mathrm{H}_{4}$ conversion rate constants $\left(k_{5}^{\prime}+k_{6}^{\prime}\right)$ were $\sim 5$ times larger than for $\mathrm{CH}_{4}$ conversion $\left(k_{1}^{\prime}+k_{2}^{\prime}\right)$ for surface-mediated pathways prevalent under anhydrous conditions, even though $\mathrm{C}-\mathrm{H}$ bonds in $\mathrm{C}_{2} \mathrm{H}_{4}$ are significantly stronger than in $\mathrm{CH}_{4}$ reactants. This high $\mathrm{C}_{2} \mathrm{H}_{4}$ reactivity appears to reflect the specific and preferential binding of $\mathrm{C}_{2} \mathrm{H}_{4}$ on oxide surfaces, ${ }^{41}$ compared with $\mathrm{CH}_{4}$ and $\mathrm{C}_{2} \mathrm{H}_{6} \cdot{ }^{30}$ In contrast, $\mathrm{C}_{2} \mathrm{H}_{4}$ was found to be less reactive than $\mathrm{CH}_{4}$ via $\mathrm{OH}$-mediated pathways $\left(\left(k_{5}^{\prime}+k_{6}^{\prime}\right) /\left(k_{1}^{\prime}+k_{2}^{\prime}\right) \sim 0.7\right.$; Table 2 ). This reflects the homolytic $\mathrm{C}-\mathrm{H}$ bond activation routes involved in $\mathrm{OH}$-mediated pathways, which rigorously reflect the relative energies of the $\mathrm{C}-\mathrm{H}$ bonds involved in the activation of $\mathrm{CH}_{4}$ and $\mathrm{C}_{2} \mathrm{H}_{4}$. The reported rate of homogeneous $\mathrm{H}$ abstraction from $\mathrm{C}_{2} \mathrm{H}_{4}$ by $\mathrm{OH}$ radicals is also smaller than for $\mathrm{CH}_{4}{ }^{38}$ and the ratio of $\mathrm{C}_{2} \mathrm{H}_{4}$ to $\mathrm{CH}_{4}$ conversion rates reported here $(0.7$ at $1073 \mathrm{~K})$ is very similar to that reported for gasphase radical reactions $\left(k_{\mathrm{C}_{2} \mathrm{H}_{4}}^{\mathrm{OH}} / k_{\mathrm{CH}_{4}}^{\mathrm{OH}}=0.8\right) .{ }^{14,38}$ These low $k_{\mathrm{C}_{2} \mathrm{H}_{4}} / k_{\mathrm{CH}_{4}}$ ratios reflect the stronger $\mathrm{C}-\mathrm{H}$ bonds in $\mathrm{C}_{2} \mathrm{H}_{4}$ compared with $\mathrm{CH}_{4}$, as well as the introduction of homogeneous pathways that do not involve surface sites and the concomitant preferential binding of $\mathrm{C}_{2} \mathrm{H}_{4}$. Surface-mediated pathways that prevail under anhydrous conditions account for the high reactivity of $\mathrm{C}_{2} \mathrm{H}_{4}$ during OCM reactions and for the preferential removal of these valuable products as $\mathrm{CH}_{4}$ conversion increases. 

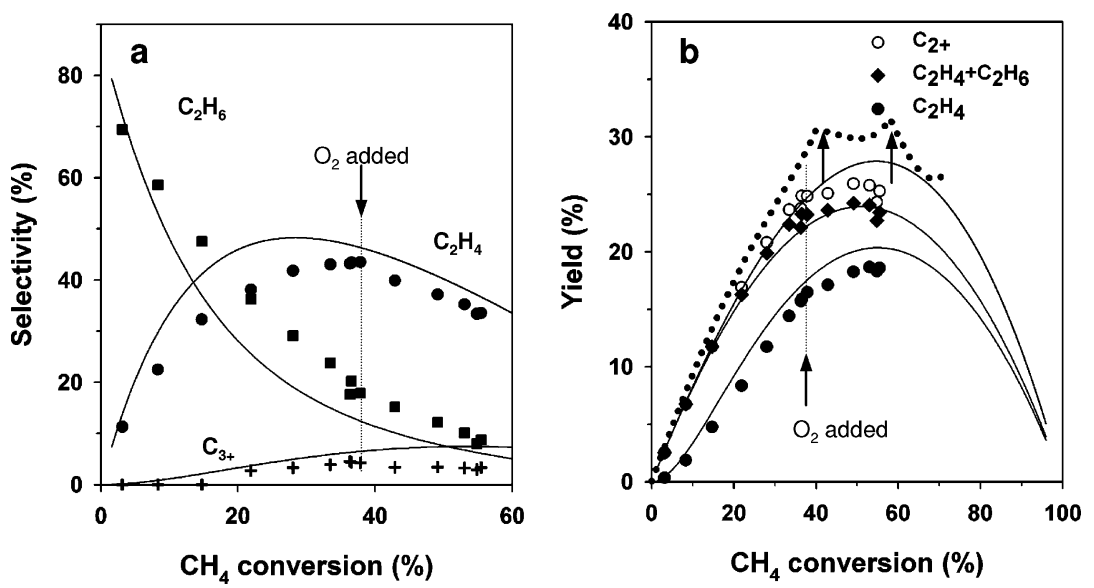

Figure 11. Product selectivities (a) and yields (b) as a function of $\mathrm{CH}_{4}$ conversion measured in a recirculating batch reactor. The solid curves denote model prediction with Scheme 1 and rate constants in Table 2 and the dotted curve denotes the ChemKin model including quasi-equilibrated $\mathrm{OH}$ radical formation $\left(0.02 \mathrm{~g}, 1073 \mathrm{~K}\right.$, volume: $550 \mathrm{~cm}^{3}, 4.0 \mathrm{kPa} \mathrm{CH}, 1.3 \mathrm{kPa} \mathrm{O}$ (initial), $1.5 \mathrm{kPa} \mathrm{O}$ (added), total pressure $101 \mathrm{kPa}$, balance $\mathrm{He}$, ChemKin model: $1073 \mathrm{~K}, 10 \mathrm{kPa} \mathrm{CH}_{4}, 1.7 \mathrm{kPa} \mathrm{O}_{2}$, total pressure $101 \mathrm{kPa}$ ).

Small concentrations of higher hydrocarbons (predominantly $\mathrm{C}_{3} \mathrm{H}_{6}$ ) were detected as $\mathrm{CH}_{4}$ conversion increased, because recombination reactions of methyl radicals with $\mathrm{C}_{2}$ products and respective radicals become important as $\mathrm{C}_{2}$ concentrations increase (e.g., $\mathrm{C}_{2} \mathrm{H}_{3}{ }^{\cdot}+\mathrm{CH}_{3}{ }^{\cdot} \rightarrow \mathrm{C}_{3} \mathrm{H}_{6} ; \mathrm{C}_{2} \mathrm{H}_{4}+\mathrm{CH}_{3}{ }^{\cdot} \rightarrow \mathrm{C}_{3} \mathrm{H}_{7}{ }^{\cdot}$ $\left.\rightarrow \mathrm{C}_{3} \mathrm{H}_{6}+\mathrm{H}^{\circ}\right)$. Therefore, we include $\mathrm{C}_{3} \mathrm{H}_{6}$ reactions in Scheme 1. The rate of $\mathrm{C}_{3}$ formation and oxidation were probed by isotopic tracing using ${ }^{13} \mathrm{CH}_{4} /{ }^{12} \mathrm{C}_{3} \mathrm{H}_{6} / \mathrm{O}_{2}\left(/ \mathrm{H}_{2} \mathrm{O}\right)$ reactants. The $k_{7}^{\prime} /$ $k_{1}^{\prime}$ ratios for $\mathrm{OH}$-mediated pathways $(\sim 2)$ of $\mathrm{C}_{3} \mathrm{H}_{6}$ are much smaller than for surface-mediated pathways $(\sim 12)$ (Table 2$)$. The rate constants for $\mathrm{C}_{3} \mathrm{H}_{6}$ oxidation $\left(k_{7}^{\prime}\right)$ are much larger than for $\mathrm{C}_{2} \mathrm{H}_{6}\left(k_{4}^{\prime}\right)$ or $\mathrm{C}_{2} \mathrm{H}_{4}\left(k_{6}^{\prime}\right)$ oxidation via the respective $\mathrm{OH}-$ mediated and surface-catalyzed pathways, consistent with the weak nature of allylic $\mathrm{C}-\mathrm{H}$ bonds in $\mathrm{C}_{3} \mathrm{H}_{6}\left(372 \mathrm{~kJ} \mathrm{~mol}^{-1}\right){ }^{32}$ These results suggest that chain growth contributes significantly to yield losses in OCM reactions, as proposed previously. ${ }^{13}$ The observed selectivity to higher hydrocarbons $\left(\mathrm{C}_{3+}\right)$ was relatively low $(\sim 4.5 \%)$ at the modest pressures used here $\left(4-10 \mathrm{kPa} \mathrm{CH}_{4}\right)$. Higher pressures, required for relevant OCM practice, favor radical recombination and may lead to higher $\mathrm{C}_{3+}$ formation rates and to more significant $\mathrm{C}_{2}$ yield losses via rapid oxidation of higher alkanes and alkenes.

Figure 11, panels a and b, shows measured OCM product selectivities and yields, together with predictions from a kinetic treatment based on the steps in Scheme 1 and independently measured rate constants for surface-catalyzed and $\mathrm{OH}$-mediated routes (Table 2). Maximum $\mathrm{C}_{2}$ and $\mathrm{C}_{2}+$ yields were $24 \%$ and $26 \%$ (Figure $11 \mathrm{~b}$ ), respectively, similar to the highest reported yields. ${ }^{8}$ The network in Scheme 1 accurately describes measured yields as a function of $\mathrm{CH}_{4}$ conversion (Figure 11b). In contrast, rate constants for surface-mediated pathways predict maximum $\mathrm{C}_{2+}$ yield of only $14 \%,{ }^{18}$ because of the high $k_{6}^{\prime} / k_{1}^{\prime}$ $(\sim 4)$ and $k_{7}^{\prime} / k_{1}^{\prime}(\sim 12)$ ratios for the surface-mediated pathways that prevail under anhydrous conditions. Maximum attainable $\mathrm{C}_{2+}$ yields are limited in practice by the relative reactivity of $\mathrm{C}_{2}$ (and $\mathrm{C}_{3+}$ ) and $\mathrm{CH}_{4}$ at conditions where highly reactive $\mathrm{OH}$ radicals predominantly account for the kinetically-relevant $\mathrm{H}$-abstraction from hydrocarbon reactants and products.

3.5.2. Simulation of OH-Mediated Pathway Model and Attainable OCM Yields. Next, we report simulation results to illustrate the effects of $\mathrm{OH}$ radical formation on OCM rates and selectivities, using available ChemKin $\operatorname{codes}^{26}$ and reported rate and equilibrium constants for relevant gas phase reactions. ${ }^{14}$ Previous studies ${ }^{13,24,42,43}$ have treated the coupling of homogeneous and surface-catalyzed routes via the formation of organic radicals through $\mathrm{C}-\mathrm{H}$ bond activation on $\mathrm{O}_{\mathrm{s}}{ }^{*}$ species. Here, we include a fast surface reaction that forms equilibrium concentrations of $\mathrm{OH}$ radicals, which are not attainable via purely homogeneous kinetic routes

$$
\mathrm{O}_{2}+2 \mathrm{H}_{2} \mathrm{O} \rightleftarrows 4 \mathrm{OH}^{\bullet}
$$

This is implemented by using arbitrarily large pre-exponential factors for the forward and reverse steps of this reaction, while maintaining their rate ratio consistent with the thermodynamics of the overall reaction. Figure $11 \mathrm{~b}$ shows $\mathrm{C}_{2}$ yields predicted by these simulations. At conditions similar to those used in our experiments $\left(10 \mathrm{kPa} \mathrm{CH}, \mathrm{O}_{2} 1.7 \mathrm{kPa}, 1073 \mathrm{~K}\right)$ and with $\mathrm{O}_{2}$ addition after its depletion (the arrows in Figure 11b), $\mathrm{C}_{2+}$ yields are similar to measured values $(\sim 30 \%$, Figure $11 \mathrm{~b})$. This agreement with experiment is reassuring in view of the absence of undesired side reactions of $\mathrm{C}_{2}$ products on catalyst surfaces in this model and suggests that $\mathrm{OH}$ radicals indeed account for most $\mathrm{H}$-abstraction events at relevant $\mathrm{H}_{2} \mathrm{O}$ concentrations.

These simulations were extended to reactant pressures and temperatures unattainable in our experimental setup within safe operating regimes but potentially useful in OCM industrial practice. Throughout these simulations, we have maintained quasi-equilibrated $\mathrm{OH}$ radical formation steps; therefore, $\mathrm{C}_{2}$ yields represent upper bounds, because they neglect less selective surface-mediated steps or $\mathrm{OH}$ concentrations below equilibrium levels. The inlet ratio of $\mathrm{CH}_{4}$ to $\mathrm{O}_{2}$ was set to 6 , as in our experiments, and $\mathrm{O}_{2}$ was added after its pressure decreased below $0.1 \mathrm{kPa}$ until $\mathrm{C}_{2}$ yields reached a maximum value. Figure 12 shows the highest attained $\mathrm{C}_{2}$ yields at each temperature and $\mathrm{CH}_{4}$ inlet pressure. Higher $\mathrm{CH}_{4}$ pressures decreased $\mathrm{C}_{2}$ yields because they favor chain growth and the formation of reactive $\mathrm{C}_{3}$ species, which form $\mathrm{CO}_{x}$ more rapidly than $\mathrm{CH}_{4}$ or $\mathrm{C}_{2} \mathrm{H}_{6}$. Temperatures above $1073 \mathrm{~K}$ increased $\mathrm{C}_{2}$ yields, because the activation barrier for $\mathrm{OH}$ reactions with $\mathrm{CH}_{4}$ is higher than for the respective reaction with $\mathrm{C}_{2} \mathrm{H}_{6}, \mathrm{C}_{2} \mathrm{H}_{4}$, and $\mathrm{C}_{3+}$ hydrocarbons. ${ }^{14}$ These simulations show, however, an optimum intermediate temperature for maximum $\mathrm{C}_{2}$ yields (e.g., $\sim 1250 \mathrm{~K}$ at $10 \mathrm{kPa} \mathrm{CH}_{4}$ ) partly because, for a given conversion, the ratio of the concentrations of $\mathrm{C}_{2} \mathrm{H}_{3}$ to $\mathrm{CH}_{3}$ increases with temperature so that higher hydrocarbon formation $\left(\mathrm{C}_{3}, \mathrm{C}_{4}\right.$; e.g., $\mathrm{CH}_{3}+\mathrm{C}_{2} \mathrm{H}_{3} \rightarrow \mathrm{C}_{3} \mathrm{H}_{6}$ ) (and their subsequent combustion) becomes comparatively faster than $\mathrm{C}_{2}$ formation $\left(\mathrm{CH}_{3}+\mathrm{CH}_{3}\right.$ $\rightarrow \mathrm{C}_{2} \mathrm{H}_{6}$ ) in this kinetic model. In practice, the higher measured activation energies for surface-mediated pathways $(290 \mathrm{~kJ}$ 


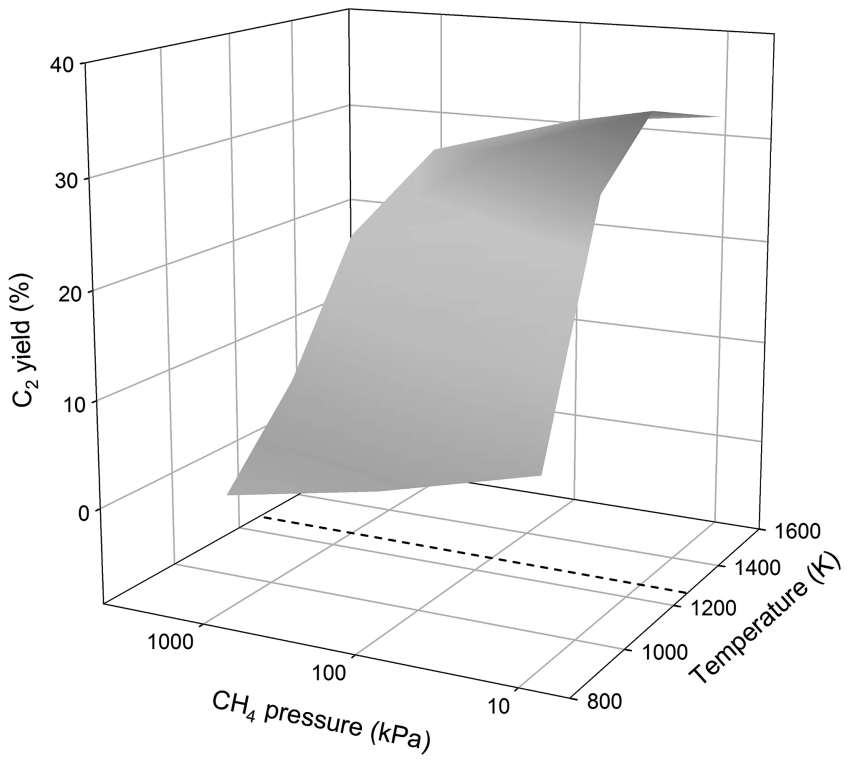

Figure 12. Maximum $\mathrm{C}_{2}$ yield calculated by ChemKin simulation, as a function of $\mathrm{CH}_{4}$ pressure and reaction temperature using a reported kinetic database. ${ }^{14}$ Dashed line indicates the temperature giving the highest $\mathrm{C}_{2}$ yield $\left(\mathrm{CH}_{4} / \mathrm{O}_{2}=6 . \mathrm{O}_{2}\right.$ addition after its reduction to $<0.1$ $\mathrm{kPa}$ to reach the maximum $\mathrm{C}_{2}$ yield).

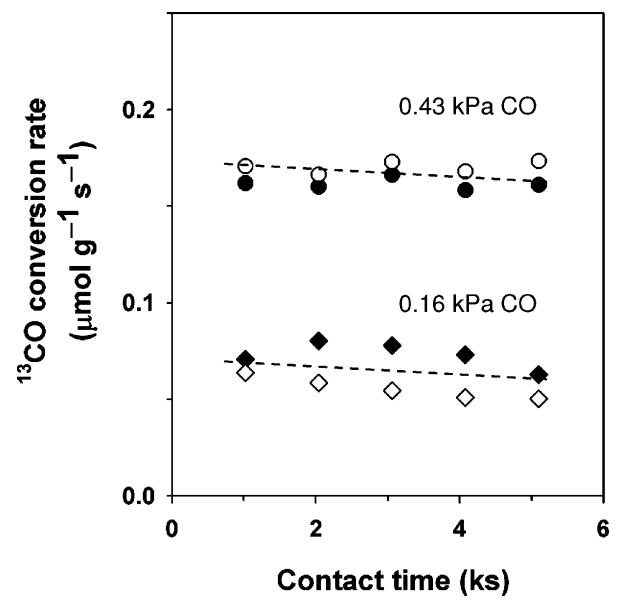

Figure 13. ${ }^{13} \mathrm{CO}$ conversion rate as a function of contact time during the reaction of $\left.{ }^{12} \mathrm{CH}_{4} /{ }^{13} \mathrm{CO} / \mathrm{O}_{2} / / \mathrm{H}_{2} \mathrm{O}\right)$ mixture measured in a recirculating reactor $\left(0.02 \mathrm{~g}, 1073 \mathrm{~K}\right.$, volume: $550 \mathrm{~cm}^{3}, 10.7 \mathrm{kPa}{ }^{12} \mathrm{CH}_{4}, 1.8 \mathrm{kPa}$ $\mathrm{O}_{2}$, total pressure $101 \mathrm{kPa}$, balance $\mathrm{He},(\bullet) 0.43 \mathrm{kPa}{ }^{13} \mathrm{CO}$; (O) 0.43 $\mathrm{kPa}{ }^{13} \mathrm{CO}, 0.4 \mathrm{kPa} \mathrm{H} \mathrm{H}_{2} \mathrm{O} ;(\diamond): 0.16 \mathrm{kPa}{ }^{13} \mathrm{CO} ;(\diamond) 0.16 \mathrm{kPa}{ }^{13} \mathrm{CO}, 0.4$ $\mathrm{kPa} \mathrm{H}_{2} \mathrm{O}$ ).

$\mathrm{mol}^{-1}$ ) compared with OH-mediated pathways $\left(161 \mathrm{~kJ} \mathrm{~mol}^{-1}\right.$; Figure 3 ) would lead to increasing contributions from less selective surface-mediated routes as the reaction temperature increases, making these higher $\mathrm{C}_{2}$ yields at high temperature unattainable.

We have also examined pathways for $\mathrm{CO}$ oxidation during OCM using ${ }^{12} \mathrm{CH}_{4} /{ }^{13} \mathrm{CO} / \mathrm{O}_{2}$ isotopic mixtures (Figure 13) with and without added $\mathrm{H}_{2} \mathrm{O} ; \mathrm{H}_{2} \mathrm{O}$ can introduce water-gas shift pathways $\left(\mathrm{CO}+\mathrm{H}_{2} \mathrm{O} \rightleftarrows \mathrm{CO}_{2}+\mathrm{H}_{2}\right)$ that form $\mathrm{CO}_{2}$ without direct involvement of $\mathrm{O}_{2}$. Measured ${ }^{13} \mathrm{CO}$ oxidation rates were proportional to ${ }^{13} \mathrm{CO}$ pressure and independent of $\mathrm{H}_{2} \mathrm{O}$ concentrations. These results indicate that $\mathrm{CO}$ oxidation occurs via surface-mediated pathways on $\mathrm{O}_{\mathrm{s}} *$ species that also activate $\mathrm{C}-\mathrm{H}$ bonds and that water-gas shift reactions do not occur at detectable rates on $\mathrm{Mn} / \mathrm{Na}_{2} \mathrm{WO}_{4} / \mathrm{SiO}_{2}$ even at $>1000 \mathrm{~K}$. Firstorder $\mathrm{CO}$ oxidation rate constants (Scheme 1) are significantly larger than for $\mathrm{CH}_{4}$ activation with $\mathrm{O}_{\mathrm{s}} *\left(k_{8}^{\prime} /\left(k_{1}^{\prime}+k_{2}^{\prime}\right) \sim 7\right.$, Table

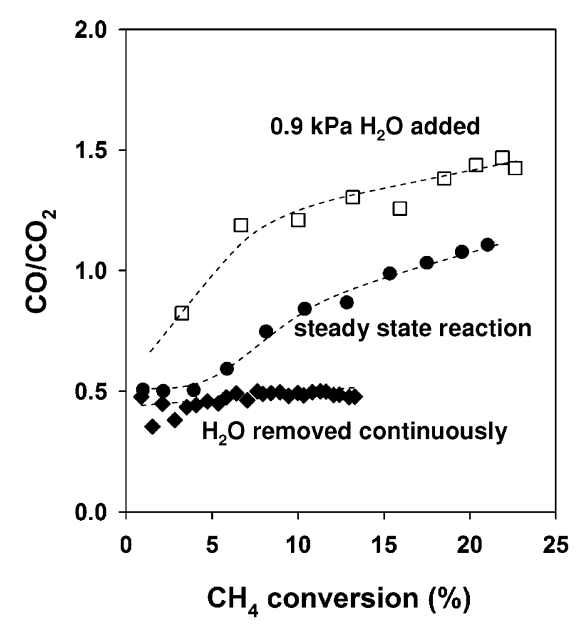

Figure 14. $\mathrm{CO} / \mathrm{CO}_{2}$ ratio as a function of $\mathrm{CH}_{4}$ conversion measured in a recirculating batch reactor $(0.02 \mathrm{~g}, 1073 \mathrm{~K}$, volume: $275-650$ $\mathrm{cm}^{3}, 10.7 \mathrm{kPa} \mathrm{CH}_{4}, 1.8 \mathrm{kPa} \mathrm{O}_{2}, 101 \mathrm{kPa}$ total pressure, balance $\mathrm{He}$, $(\diamond): \mathrm{H}_{2} \mathrm{O}$ removed continuously; $(\bullet)$ : steady state reaction $\left(\mathrm{H}_{2} \mathrm{O}\right.$ concentration increases during reaction); ( $\square$ ): $0.9 \mathrm{kPa} \mathrm{H}_{2} \mathrm{O}$ added).

2), suggesting that $\mathrm{CO}_{2}$ is formed preferentially instead of $\mathrm{CO}$ via surface-mediated pathways. The presence of $\mathrm{H}_{2} \mathrm{O}$ increased both ${ }^{12} \mathrm{CO}$ and ${ }^{12} \mathrm{CO}_{2}$ formation rates (from ${ }^{12} \mathrm{CH}_{4}$ ) because $\mathrm{OH}-$ mediated $\mathrm{CH}_{4}$ activation routes also form ${ }^{12} \mathrm{CO}$ and ${ }^{12} \mathrm{CO}_{2}\left(k_{2}^{\prime}\right.$; Scheme 1). These results also show that $\mathrm{OH}$ radicals do not react with $\mathrm{CO}$ to form $\mathrm{CO}_{2}$ either directly (to form $\mathrm{CO}_{2}$ and $\mathrm{H}$ ) or via reactions with other species derived from $\mathrm{OH}$ radicals.

Figure 14 shows measured $\mathrm{CO} / \mathrm{CO}_{2}$ ratios for experiments in which water was (i) added; (ii) allowed to accumulate during OCM; or (iii) removed as it formed in OCM reactions. $\mathrm{CO} /$ $\mathrm{CO}_{2}$ ratios remained relatively low $(\sim 0.5)$, even at high $\mathrm{CH}_{4}$ conversions, when $\mathrm{H}_{2} \mathrm{O}$ was continuously removed because prevalent surface-mediated pathways convert hydrocarbons predominantly to $\mathrm{CO}_{2}$ (step 9). As $\mathrm{H}_{2} \mathrm{O}$ formed in OCM reactions were allowed to accumulate, $\mathrm{CO} / \mathrm{CO}_{2}$ ratios increased with increasing conversion and $\mathrm{H}_{2} \mathrm{O}$ concentration. The addition of $\mathrm{H}_{2} \mathrm{O}$ to $\mathrm{CH}_{4}-\mathrm{O}_{2}$ reactants gave higher $\mathrm{CO} / \mathrm{CO}_{2}$ ratios, because $\mathrm{OH}$-mediated pathways lead to radical species that preferentially form $\mathrm{CO}$ from hydrocarbons via homogeneous pathways. $\mathrm{CH}_{4}$ and $\mathrm{C}_{2}$ oxidation in empty reactors led to very high $\mathrm{CO} / \mathrm{CO}_{2}$ ratios $(>5)$, consistent with the preferential formation and significant stability of $\mathrm{CO}$ in homogeneous oxidation pathways and with the known free radical pathways that form significant amounts of $\mathrm{CO}$ during homogeneous combustion at low temperatures. ${ }^{38}$

3.6. Effects of $\mathrm{O}_{2}$ Concentrations on Maximum Attainable $\mathrm{C}_{2}$ Yields in OCM Reactions. Low $\mathrm{O}_{2}$ pressures can improve $\mathrm{C}_{2}$ yields when $\mathrm{CH}_{4}$ activation steps that form $\mathrm{C}_{2}$ molecules $\left(r_{1}\right.$; Scheme 1) depend less sensitively on $\mathrm{O}_{2}$ pressures than the steps leading to the combustion of $\mathrm{CH}_{4}\left(r_{2}\right)$ or $\mathrm{C}_{2+}$ products $\left(r_{4}, r_{6}, r_{7}\right) .{ }^{14}$ Figure 1 , panels a and $\mathrm{b}$, shows differential $\mathrm{CH}_{4}$ conversion rates and (integral) $\mathrm{C}_{2}+$ selectivities, respectively, at two $\mathrm{O}_{2}$ pressures (open circles for $0.9 \mathrm{kPa} \mathrm{O}_{2}$; others for 1.8 $\left.\mathrm{kPa} \mathrm{O}_{2}\right) \cdot \mathrm{CH}_{4}$ conversion rates increased with $\mathrm{O}_{2}$ pressure, consistent with the rates predicted by eq 19 . Low $\mathrm{O}_{2}$ pressures led to higher $\mathrm{C}_{2}$ selectivities at $\mathrm{CH}_{4}$ conversions below $<10 \%$, but $\mathrm{C}_{2}$ selectivities at higher conversions became almost insensitive to $\mathrm{O}_{2}$ pressure. Thus, low $\mathrm{O}_{2}$ pressures seem to favor high initial $\mathrm{C}_{2}$ selectivities (i.e., $r_{1} / r_{2}$ in Scheme 1) but do not lead to higher selectivities or yields at relevant levels of $\mathrm{CH}_{4}$ conversion.

The effects of $\mathrm{O}_{2}$ concentrations on attainable $\mathrm{C}_{2}$ yields at higher $\mathrm{CH}_{4}$ conversions $(>15 \%)$ were probed in a gradientless 

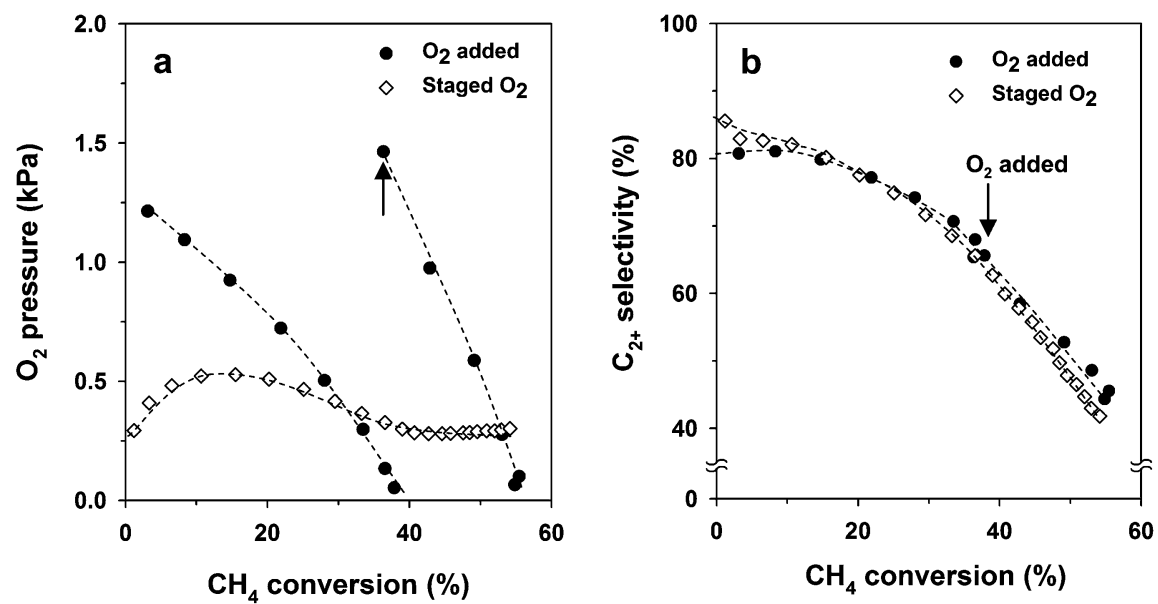

Figure 15. Effects of $\mathrm{O}_{2}$ partial pressure (a) on $\mathrm{C}_{2+}$ selectivity (b) as a function of $\mathrm{CH}_{4}$ conversion measured in a recirculating batch reactor ( 0.02 g, $1073 \mathrm{~K}$, volume: $550 \mathrm{~cm}^{3}, 4.0 \mathrm{kPa} \mathrm{CH}_{4}, 101 \mathrm{kPa}$ total pressure, balance $\mathrm{He},(\diamond) \mathrm{O}_{2}$ added; $(\diamond)$ staged $\mathrm{O}_{2}$ introduction).

TABLE 3: Rate of $\mathrm{CH}_{4}$ Conversion and Rate Ratio of $\mathrm{CH}_{4}$ Conversion for $\mathrm{C}_{2}$ Formation to $\mathrm{CO}_{x}$ Formation at Different Kinetic Regimes $\left(r_{1}, r_{2}\right.$ in Scheme 1, See Eqs 15, 29, and 31)

\begin{tabular}{clll}
\hline & surface $\mathrm{O}^{*}$ & gas phase $\mathrm{OH}$ & $\mathrm{O}_{2}$ chemisorption limiting \\
\hline$r_{\mathrm{CH}_{4}}$ & $k^{\prime}\left(\mathrm{CH}_{4}\right)^{1}\left(\mathrm{O}_{2}\right)^{0.5}$ & $k^{\prime \prime}\left(\mathrm{CH}_{4}\right)^{1}\left(\mathrm{O}_{2}\right)^{0.25}\left(\mathrm{H}_{2} \mathrm{O}\right)^{0.5}$ & $k_{\mathrm{O}_{2}}\left(\mathrm{O}_{2}\right)$ \\
$r_{1} / r_{2}$ & {$\left[\left(k^{\prime} k_{\mathrm{C}_{2}} P_{\mathrm{CH}_{4}}\right) /\left(\left(k_{\mathrm{CO}} P_{\mathrm{O}_{2}}^{1 / 2}+k_{\mathrm{CO}_{2}}\right)^{2} P_{\mathrm{O}_{2}}^{1 / 2}\right)\right]^{1 / 2}$} & {$\left[\left(k_{\mathrm{C}_{2}} k^{\prime \prime} P_{\mathrm{CH}_{4}} P_{\mathrm{H}_{2} \mathrm{O}}^{1 / 2} /\left(\left(k_{\mathrm{CO}} P_{\mathrm{O}_{2}}^{1 / 2}+k_{\mathrm{CO}_{2}}\right)^{2} P_{\mathrm{O}_{2}}^{3 / 4}\right)\right]^{1 / 2}\right.$} & $\left(k_{\mathrm{C}_{2}} k_{\mathrm{O}_{2}}\right)^{1 / 2} /\left(k_{\mathrm{CO}} P_{\mathrm{O}_{2}}^{1 / 2}+k_{\mathrm{CO}_{2}}\right)$
\end{tabular}

recirculating reactor by introducing additional oxygen, either after it was depleted or continuously as it was consumed (staged oxygen introduction). ${ }^{14,24}$ The latter strategy would rigorously mimic the continuous introduction of $\mathrm{O}_{2}$ along a tubular reactor via selectively permeable walls or distributed injectors, which have been proposed as effective strategies to improve $\mathrm{C}_{2}$ yields in OCM reactors. ${ }^{24}$ Figure $15 \mathrm{~b}$ compares $\mathrm{C}_{2+}$ selectivities as a function of $\mathrm{CH}_{4}$ conversion for the $\mathrm{O}_{2}$ pressure temporal profiles in Figure $15 \mathrm{a} . \mathrm{C}_{2}$ selectivities at $\mathrm{CH}_{4}$ conversions below $10 \%$ were indeed improved by staging $\mathrm{O}_{2}$ co-reactants, but such improvements became much smaller and nearly imperceptible as $\mathrm{CH}_{4}$ conversion levels increased to those required for even modest $\mathrm{C}_{2}$ yields (Figure 15b). We conclude that $\mathrm{O}_{2}$ staging strategies do not lead to practical gains in $\mathrm{C}_{2}$ yields because $\mathrm{C}-\mathrm{H}$ bond activation in $\mathrm{CH}_{4}$ and $\mathrm{C}_{3+}$ hydrocarbons depend similarly on $\mathrm{O}_{2}$ pressure, whether activation occurs via surfacemediated or $\mathrm{OH}$-mediated routes.

Next, we discuss the effects of $\mathrm{O}_{2}$ pressure on primary selectivities $\left(r_{1} / r_{2}\right)$ for the three relevant kinetic regimes (i) surface-mediated pathways (the first term in eq 19); (ii) $\mathrm{OH}-$ mediated pathways (the second term in eq 19); and (iii) pathways limited by $\mathrm{O}_{2}$ chemisorption (eq 21). When $\mathrm{O}_{2}$ chemisorption becomes irreversible (step 20), eqs 10-12 and 21 lead to primary $C_{2}$ selectivities given by

$$
\frac{r_{\mathrm{C} 2}}{r_{\mathrm{CO}}+r_{\mathrm{CO}_{2}}}=\frac{1}{2}\left(\sqrt{1+\frac{4 k_{\mathrm{C}_{2}} k_{\mathrm{O}_{2}}}{\left(k_{\mathrm{CO}} P_{\mathrm{O}_{2}}^{1 / 2}+k_{\mathrm{CO}_{2}}\right)^{2}}}-1\right)
$$

which becomes, at high values of these selectivity ratios $(>4)$ :

$$
\frac{r_{\mathrm{C} 2}}{r_{\mathrm{CO}}+r_{\mathrm{CO}_{2}}}=\frac{\sqrt{k_{\mathrm{C}_{2}} k_{\mathrm{O}_{2}}}}{\left(k_{\mathrm{CO}} P_{\mathrm{O}_{2}}^{1 / 2}+k_{\mathrm{CO}_{2}}\right)}
$$

The equations for these ratios when OCM reactions occur via the three routes mentioned above are shown in Table 3 . The effects of $\mathrm{O}_{2}$ pressure on selectivity are stronger for $\mathrm{OH}-$ mediated pathways (eq 29, $r_{1} / r_{2} \sim\left(\mathrm{A}^{2} P_{\mathrm{O}_{2}}^{3 / 4}\right)^{-1}$, where $A=$
$k_{\mathrm{CO}} P_{\mathrm{O}_{2}}^{1 / 2}+k_{\mathrm{CO}_{2}}$ ) than for surface-mediated pathways (eq 15, $r_{1} /$ $\left.r_{2} \sim\left(\mathrm{A}^{2} P_{\mathrm{O}_{2}}^{1 / 2}\right)^{-1}\right)$. For $\mathrm{O}_{2}$-limiting pathways, this selectivity ratio becomes proportional to $r_{1} / r_{2} \sim(\mathrm{A})^{-2}$ (eq 31) and least sensitive to $\mathrm{O}_{2}$ pressure. This accounts, at least in part, for the preferential effects of $\mathrm{O}_{2}$ pressure on selectivity at low conversions (Figure 1) and for the apparent insensitivity to $\mathrm{O}_{2}$ pressures at high conversions that lead to irreversible $\mathrm{O}_{2}$ chemisorption steps and low $\mathrm{O}_{\mathrm{s}} *$ coverages. These trends reflect, in turn, the concurrent decrease in $\mathrm{O}_{2}$ chemisorption rates and the increase in the rate of scavenging of chemisorbed oxygen via $\mathrm{OH}$-mediated $\mathrm{CH}_{4}$ activation pathways, which become faster as $\mathrm{H}_{2} \mathrm{O}$ concentrations increase with increasing conversion levels.

We probe next the sensitivity of each reactant and product conversion rate $\left(r_{1}-r_{7}\right)$ to $\mathrm{O}_{2}$ pressure. In the absence of $\mathrm{H}_{2} \mathrm{O}$, surface oxygens $\left(\mathrm{O}_{\mathrm{s}}^{*}\right)$ are involved in kinetically-relevant $\mathrm{C}-\mathrm{H}$ bond activation steps for both $\mathrm{CH}_{4}$ reactants and OCM products and rates are proportional to $\mathrm{O}_{\mathrm{s}} *$ concentrations (and thus to $P_{\mathrm{O}_{2}}^{0.5}$ ) for all $\mathrm{C}-\mathrm{H}$ bond activation steps. As $\mathrm{H}_{2} \mathrm{O}$ forms during OCM reactions, quasi-equilibrated $\mathrm{H}_{2} \mathrm{O}-\mathrm{O}_{\mathrm{s}}$ * reactions form $\mathrm{OH}$ radicals that become the predominant $\mathrm{H}$-abstractors and all $\mathrm{C}-\mathrm{H}$ bond activation rates become proportional to $P_{\mathrm{O}_{2}}^{0.25}$ (eq 19) when $\mathrm{O}_{2}$ chemisorption (step 1) is quasi-equilibrated and to $P_{\mathrm{O}_{2}}^{1}$ as this latter step becomes irreversible and kinetically-relevant (Figure 8b, step 20).

The dependence of hydrocarbon conversion rates $\left(\mathrm{CH}_{4}, \mathrm{C}_{2} \mathrm{H}_{6}\right.$, $\mathrm{C}_{2} \mathrm{H}_{4}$, and $\mathrm{C}_{3} \mathrm{H}_{6}$ ) on $\mathrm{O}_{2}$ pressure is the same for all hydrocarbons and a given $\mathrm{H}$-abstractor $\left(\mathrm{OH}^{*}\right.$ or $\left.\mathrm{O}_{\mathrm{s}}{ }^{*}\right)$. The data in Figure $15 \mathrm{~b}$ show that $\mathrm{C}_{2}$ yields are essentially unaffected by $\mathrm{O}_{2}$ pressure. At $\mathrm{CH}_{4}$ conversions above $40 \%, \mathrm{C}_{2+}$ selectivities were actually lower for staged $\mathrm{O}_{2}$ introduction than for co-fed experiments. At the low $\mathrm{O}_{2}$ pressures prevalent in these staged experiments, the concurrent presence of $\mathrm{H}_{2} \mathrm{O}$ leads to irreversible and ratedetermining $\mathrm{O}_{2}$ chemisorption steps at all conversion levels; in this kinetic regime, $\mathrm{O}_{2}$ pressures do not affect primary $\mathrm{C}_{2}$ selectivities $\left(r_{1} / r_{2}\right)$ at low conversions (eq 31, Table 3 ), as discussed above. Low $\mathrm{O}_{2}$ pressures, however, decrease the rate of all surface-catalyzed reactions involving $\mathrm{O}_{\mathrm{s}}{ }^{*}$, including those leading to $\mathrm{OH}$ radicals involved in homogeneous $\mathrm{C}-\mathrm{H}$ bond activation steps, because they all have positive kinetic orders 
in $\mathrm{O}_{2}$ (eqs 19 and 21). The consequent decrease in $\mathrm{CH}_{3}$ concentrations leads to lower $\mathrm{C}_{2}$ selectivities, because of the bimolecular nature of $\mathrm{CH}_{3}$ recombination steps that form $\mathrm{C}_{2}$ (eq 10), which depend on $\mathrm{CH}_{3}$ concentrations more strongly than the unselective unimolecular pathways that form $\mathrm{CO}$ from $\mathrm{CH}_{3}$ radicals (eqs 11 and 12).

We note that similar experiments and kinetic analyses on $\mathrm{SrO}_{x} / \mathrm{La}_{2} \mathrm{O}_{3}$ solids, which also catalyze $\mathrm{OCM},{ }^{44}$ did not detect significant effects of $\mathrm{H}_{2} \mathrm{O}$ on rates or selectivities. These catalysts gave lower maximum yields than $\mathrm{Mn} / \mathrm{Na}_{2} \mathrm{WO}_{4} / \mathrm{SiO}_{2}$. These findings indicate that $\mathrm{OH}$ formation rates depend sensitively on the identity of the catalyst and that the unique selectivity and yields reported on $\mathrm{Mn} / \mathrm{Na}_{2} \mathrm{WO}_{4} / \mathrm{SiO}_{2}$ reflect, at least in part, its ability to form quasi-equilibrated $\mathrm{OH}$ radical concentrations from $\mathrm{H}_{2} \mathrm{O}-\mathrm{O}_{2}$ at conditions also required for surface-mediated OCM pathways.

Maximum OCM yields would require conditions in which $\mathrm{OH}$ radicals act as the predominant $\mathrm{H}$-abstractors, but which also maintain quasi-equilibrated $\mathrm{O}_{2}$ chemisorption steps. $\mathrm{OH}-$ mediated pathways are more sensitive to $\mathrm{O}_{2}$ pressure than surface $\mathrm{O}_{\mathrm{s}}{ }^{*}$-mediated pathways; thus, decreasing $\mathrm{O}_{2}$ pressures would improve selectivities as long as $\mathrm{OH}$ concentrations can be maintained at equilibrium levels, a requirement that can be met only at sufficiently high $\mathrm{O}_{2}$ pressures. These findings and interpretations suggest that intermediate $\mathrm{O}_{2}$ pressures are optimal and that these optimal values depend sensitively on the prevalent $\mathrm{H}_{2} \mathrm{O}$ concentration at a given point in the reactor and on its concomitant effect on the rate $\mathrm{OH}$-mediated pathways. The consequences of these optimization strategies can be accurately probed as a result of the unprecedented detail in the kinetic models that we report here for the first time and of the use of experimental reactors that can be used to rigorously validate the kinetic models and their use in these staging protocols.

\section{Conclusions}

Attainable $\mathrm{C}_{2}$ yields for OCM are limited by the intrinsic reactivity of $\mathrm{C}_{2}$ (and $\mathrm{C}_{3+}$ ) relative to $\mathrm{CH}_{4}$ at conditions where highly reactive $\mathrm{OH}$ radicals are responsible for the kineticallyrelevant $\mathrm{H}$-abstraction from each hydrocarbon. Our rigorous kinetic measurements revealed the supplementary and predominant $\mathrm{C}-\mathrm{H}$ activation pathways mediated by $\mathrm{OH}$ free radicals formed from $\mathrm{H}_{2} \mathrm{O} / \mathrm{O}_{2}$ mixtures during OCM on $\mathrm{Mn} / \mathrm{Na}_{2} \mathrm{WO}_{4} /$ $\mathrm{SiO}_{2}$. Isotope effects and scrambling experiments using $\mathrm{CD}_{4} /$ $\mathrm{CH}_{4}$ and/or $\mathrm{D}_{2} \mathrm{O} / \mathrm{H}_{2} \mathrm{O}$ showed that $\mathrm{C}-\mathrm{H}$ bond activation was irreversible and kinetically-relevant both in the presence and the absence of $\mathrm{H}_{2} \mathrm{O}$, and that $\mathrm{O}-\mathrm{H}$ bond activation steps were not involved in the kinetically-relevant steps. Scrambling experiments using ${ }^{18} \mathrm{O}_{2}-{ }^{16} \mathrm{O}_{2}$ showed that $\mathrm{O}_{2}$ dissociation was quasi-equilibrated only at high $\mathrm{O}_{2} / \mathrm{H}_{2} \mathrm{O}$ ratios. At low $\mathrm{O}_{2} / \mathrm{H}_{2} \mathrm{O}$ ratios, $\mathrm{O}_{2}$ chemisorption steps become no longer quasiequilibrated and nearly irreversible, and limit the overall conversion rates, where the OCM selectivity is insensitive to $\mathrm{O}_{2}$ pressures. Isotopic tracer studies using ${ }^{13} \mathrm{CH}_{4} / \mathrm{O}_{2}\left(/ \mathrm{H}_{2} \mathrm{O}\right)$ with ${ }^{12} \mathrm{C}_{2} \mathrm{H}_{6},{ }^{12} \mathrm{C}_{2} \mathrm{H}_{4}$ or ${ }^{12} \mathrm{C}_{3} \mathrm{H}_{6}$ mixtures showed that rate constant ratios $k_{\mathrm{C}_{2} \mathrm{H}_{6}} / k_{\mathrm{CH}_{4}}$ and $k_{\mathrm{C}_{2} \mathrm{H}_{4}} / k_{\mathrm{CH}_{4}}$ were smaller for $\mathrm{OH}$-mediated pathways than for surface mediated pathways, consistent with improved $\mathrm{C}_{2}$ selectivities and yields in the presence of $\mathrm{H}_{2} \mathrm{O}$, which are ascribed to (1) enhanced steady-state $\mathrm{CH}_{3}$ radical concentrations introduced by $\mathrm{OH}$-mediated pathways and the second-order nature of $\mathrm{CH}_{3}$ radicals for their coupling, compared to the first-order nature of their oxidation process, (2) the reactive nature of $\mathrm{OH}$ radicals which give unselective $\mathrm{H}$ abstraction to intrinsic $\mathrm{C}-\mathrm{H}$ bond strengths in hydrocarbons compared to $\mathrm{O}_{\mathrm{s}}^{*}$ as less reactive $\mathrm{H}$-abstractors, and (3) avoiding strong adsorption of $\mathrm{C}_{2} \mathrm{H}_{4}$ on surfaces that favor its oxidation, by the gas-phase $\mathrm{OH}$ radical routes. $\mathrm{C}_{3}$ and higher hydrocarbon formation, which have bimolecular nature of carbonaceous radicals and are favored at high pressures, in turn lead to rapid combustion and reduce maximum attainable yields. Mechanismbased rate equations comprising rate-determining $\mathrm{C}-\mathrm{H}$ bond activation by surface-mediated and $\mathrm{OH}$-mediated routes accurately describes the effects of pressure and residence time on rates and attainable $\mathrm{C}_{2}$ yields. The maximum $\mathrm{C}_{2}$ yields measured were unaffected by staging introduction of $\mathrm{O}_{2}$ in OCM reactors because of the same dependence of $\mathrm{O}_{2}$ pressure on the $\mathrm{C}-\mathrm{H}$ bond activation rates for $\mathrm{CH}_{4}, \mathrm{C}_{2} \mathrm{H}_{6}$, and $\mathrm{C}_{2} \mathrm{H}_{4}$ and the insensitivity of OCM selectivity to $\mathrm{O}_{2}$ pressure at $\mathrm{O}_{2}$ chemisorption limiting conditions.

Acknowledgment. This study was supported by BP as part of the Methane Conversion Cooperative Research Program at the University of California at Berkeley. The authors acknowledge Drs. Ayman D. Allian, Aditya Bhan, Josef Macht, and Xinyu Xia, and Mr. Rajamani Gounder of the University of California at Berkeley for extensive technical comments and suggestions about the contents and interpretations in this manuscript. The technical guidance of Drs. Theo Fleisch and Sander Gaemers of BP are also acknowledged with thanks.

Supporting Information Available: Additional explanation of experimental results. This material is available free of charge via the Internet at http://pubs.acs.org.

\section{References and Notes}

(1) Keller, G. E.; Bhasin, M. M. J. Catal. 1982, 73, 9.

(2) Lunford, J. H. Catal. Today 2000, 63, 165.

(3) Lercher, J. A.; Bitter, J. H.; Steghuis, A. G.; van Ommen, J. G.; Seshan, K. In Environmental Catalysis; Jannsen, F. J. J. G., van Santen, R. A., Eds.; Imperial College Press: London, 1999; pp 103-126.

(4) Fang, X.; Li, S.; Lin, J.; Gu, J.; Yang, D. J. Mol. Catal. (China) 1992, 6, 427. 390.

(5) Wang, D.; Rosynek, M. P.; Lunsford, J. H. J. Catal. 1995, 155,

(6) Pak, S.; Qiu, P.; Lunsford, J. H. J. Catal. 1998, 79, 222.

(7) Pak, S.; Lunsford, J. H. Appl. Catal., A 1998, 168, 131.

(8) Palermo, A.; Vazquez, J. P. H.; Lee, A. F.; Tikhov, M. S.; Lambert,

R. M. J. Catal. 1998, 177, 259.

(9) Ito, T.; Wang, J.-X.; Lin, C.-H.; Lunsford, J. H. J. Am. Chem. Soc. 1985, 107, 5062 .

(10) Campbell, K. D.; Lunsford, J. H. J. Phys. Chem. 1988, 92, 5792.

(11) Morales, E.; Lunsford, J. H. J. Catal. 1989, 118, 255.

(12) Labinger, J. A. Catal. Lett. 1988, 1, 371.

(13) Labinger, J. A.; Ott, K. C. J. Phys. Chem. 1987, 91, 2682.

(14) Mims, C. A.; Mauti, R.; Dean, A. M.; Rose, K. D. J. Phys. Chem.

1994, 98, 13357.

(15) Reyes, S. C.; Iglesia, E.; Kelkar, C. P. Chem. Eng. Sci. 1993, 48, 2643.

(16) Reyes, S. C.; Kelkar, C. P.; Iglesia, E. Catal. Lett. 1993, 19, 167.

(17) Batiot, C.; Hodnett, B. K. Appl. Catal., A 1996, 137, 179.

(18) Takanabe, K.; Iglesia, E. Angew. Chem., Int. Ed. 2008, 47, 7689.

(19) Anderson, L. C.; Xu, M.; Mooney, C. E.; Rosynek, M. P.; Lunsford,

J. H. J. Am. Chem. Soc. 1993, 115, 6322.

(20) Hewett, K. B.; Anderson, L. C.; Rosynek, M. P.; Lunsford, J. H. J. Am. Chem. Soc. 1996, 118, 6992.

(21) Hewett, K. B.; Rosynek, M. P.; Lunsford, J. H. Catal. Lett. 1997, 45,125 .

(22) Gaffney, A. M. U.S. Patent, 4788372.

(23) Leyshon, D. W. U.S. Patent, 4801762.

(24) Androulakis, I. P.; Reyes, S. C. AIChE J. 1999, 45, 860.

(25) Coronas, J.; Santamaría, J. Catal. Today 1999, 51, 377.

(26) ChemKin, Reaction Design CHEMKIN 4.1.

(27) Brunauer, S.; Emmett, P. H.; Teller, E. J. Am. Chem. Soc. 1938, $60,309$.

(28) Iglesia, E.; Baumgartner, J. E.; Price, G. L.; Rose, K. D.; Robbins, J. L. J. Catal. 1990, 125, 95.

(29) Roos, J. A.; Korf, S. J.; Veehof, R. H. J.; van Ommen, J. G.; Ross, J. R. H. Appl. Catal. 1989, 52, 131.

(30) Lacombe, S.; Zanthoff, H.; Mirodatos, C. J. Catal. 1995, 155, 106. 

77.

(31) Otsuka, K.; Said, A. A.; Jinno, K.; Komatsu, T. Chem. Lett. 1987,

(32) Blanksby, S. J.; Ellison, G. B. Acc. Chem. Res. 2003, 36, 255.

(33) Hutchings, G. J.; Woodhouse, J. R. J. Chem. Soc. Faraday Trans. $1 \mathbf{1 9 8 9}, 85,2507$.

(34) The rate constant optimization is calculated using Athena Visual Studio Version: 10.7. Stewart and Associates Engineering Software, Inc. More details are available in Supporting Information (Scheme S1, Table S1, and Figure S2).

(35) Chase, M. W., Jr. J. Phys. Chem. Ref. Data 1998, 1 NIST-JANAF Themochemical Tables, Fourth Edition, Monograph 9.

(36) Masgrau, L.; Gonzalez-Lafont, A.; Lluch, J. M. J. Chem. Phys. 2001, 115,4515 .

(37) Masgrau, L.; Gonzalez-Lafont, A.; Lluch, J. M. J. Chem. Phys. 2001, 114, 2154.

(38) GRI-Mech v.3.0. Smith, G. P.; Golden, D. M.; Frenklach, M.; Moriarty, N. W.; Eiteneer, B.; Goldenberg, M.; Bowman, C. T.; Hanson,
R. K.; Song, S.; Gardiner, W. C., Jr.; Lissianski, V. V.; Qin, Z. http:// www.me.berkeley.edu/gri_mech/.

(39) Boudart, M.; Djéga-Mariadassou, G. Kinetics of Heterogeneous Catalytic Reactions; Princeton University Press: Princeton, NJ, 1984; p 121.

(40) Zalc, J. M.; Green, W. H.; Iglesia, E. Ind. Eng. Chem. Res. 2006, 45, 2677.

(41) Dumesic, J. A.; Rudd, D. F.; Aparicio, L. M.; Rekoske, J. E.; Treviño, A. A. The Microkinetics of Heterogeneous Catalysis; American Chemical Society: Washinton, DC, 1993.

(42) Su, Y. S.; Ying, J. Y.; Green, W. H., Jr. J. Catal. 2003, $218,321$.

(43) Couwenberg, P. M.; Chen, Q.; Marin, G. B. Ind. Eng. Chem. Res. 1996, 35, 3999.

(44) DeBoy, J. M.; Hicks, R. F. J. Chem. Soc., Chem. Commun. 1988, 982.

JP9001302 